\title{
$\mathrm{XX}$.
}

Aus der chirurgischen Klinik in Marburg.

\section{Experimentelle Beiträge zur Anatomie und Pathologie des Gelenkknorpels.}

$$
\text { Von }
$$

Dr. Rudolf Seggel, Oberarzt des Krankenhauses in Geestemünde.

I. Verhalten des Knorpels bei Übertragung in die Bauchböhle.

Das Knorpelgewebe hat in seiner Eigenschaft als gefäßloses, einzig und allein durch den diffundierenden Saftstrom ernährtes Gewebe schon seit langer Zeit die Aufmerksamkeit der Pathologen und Chirurgen auf sich gezogen. Besonders die Reaktion desselben auf entzündliche Agentien, auf traumatisehe Eingriffe war Gegenstand eingehendster Untersuchungen. Hat überhaupt der Knorpel die Fähigkeit, in Entzündung überzugehen?

Mentzel (1815) bestreitet dies, auch Redfern bält eine Entzündung am Knorpel für unmöglich, Virchow (Archiv B. VI p. 290) spricht am Knorpel eigens von einer Entzündung gefäßloser Teile vindiciert ihm also unter den Geweben des menschlichen Körpers eine ganz eigene Rolle, äbnlich der Hornbaut. Schon die Differenz in diesen wenigen Citaten, die weiter unten noch vervollständigt werden sollen, zeigt, wie weit die Verbältnisse noch von einer Klärung entfernt sind. Das gleiche gilt für die Beteiligung des Knorpelgewebes bei der tuberkulösen Erkrankung der Knochen und Gelenke, bei der ossalen und synovialen Form der Gelenk-Tuberkulose, die erst in jüngster Zeit, wieder von Heile zum Gegenstand eingehender Untersuchungen gemacht wurde.

Diese Veröffentlichung regte mich an, etwas genauer diesem Gegenstande nachzugehen. Schon die Durchsicht der Literatur, noch mehr aber die Durchmusterung meiner Präparate der verschiedensten 
Arten von Gelenktuberkulose und deren Besprechung mit Professor Aschoff in Marburg machte es mir klar daßj ich ab ovo beginnen müßte bei der Eigenart des in Betracht kommenden Gewebes, und so stellte ich mir als erstes die Aufgabe, den Knorpel und seine Zellen unter den einfachsten Bedingungen zu studieren, seine Vitalität, seine Lebensenergie festzustellen. Da ich ausgegangen war von den Erkrankungen des Gelenkknorpels, so beschränkte ich mich auch in den folgenden Untersuchungen auf denselben und machte auf Vorschlag von Prof. Aschoff die Implantation von aus der Kontinuität des Gelenkknorpels ausgelösten Stückchen in die Bauchböhle. So zerfällt meine Arbeit in zwei Teile; im ersten will ich die Veränderungen schildern, die der Gelenkknorpel bei dieser Dislocierung erfäbrt, im zweiten die Reaktion in dem dadurch entstandenen Defekt.

Derartige Untersuchungen waren ja wohl schon vorgenommen worden, aber größtenteils nicht mit Gelenkknorpel, sondern mit $\mathrm{Ohr}$ oder Rippenknorpel, also mit einem mit Perichondrium versehenen Knorpel.

Eine, wenn auch kurze Übersicht der Literatur zeigt, wie different die Anschaunngen der einzelnen Autoren in der Deutung der erbobenen Befunde sind, wie schwer es ist, die einzelnen Ergebnisse, besonders in bezug auf die Rolle, welche das Vorhandensein oder Fehlen eines Perichondriums spielt, von einander zu sondern. Daher muß ich in der Übersicht der Literatur auch die Befunde bei Implantation und Reimplantation ron perichondrisalem Knorpel mit hereinbeziehen.

Veranlaßt wurden alle derartigen Untersuchungen wohl zuerst durch die merkwürdigen Befunde von Leopold über die Entstehung von Knorpelgeschwülsten in der Lunge bei Einbringung von zerkleinertem embryonalen Knorpel in den Blutkreislauf, Untersuchungen, die er dann noch weiter auf die Übertragung ron embryonalem Knorpel unter den verschiedensten Bedingungen ausdehnte. So fand er bei Implantation der embryonalen Unterschenkelepiphyse am 4. Tag Vermehrung der Zellen, die am nicht implantierten Kontrollpräparat fehlte, bei Implantation des Rippenknorpels von reifen, $7-8 \mathrm{~cm}$ langen Embryonen am 12. und 18. Tag rapides Weiterwachsen und zwar auf Teile des Querschnitts beschränkt mit 8 und noch mehr Kernen in einem Zelleib (Knorpelhöhle). Auch nach 24 und 56 Tagen bestand lebhafteste Vermehrung mit unregelmäßiger Verkalkung in der Peripherie und im Centrum. Bei Implantation vom Epiphysenknorpel von $6 \mathrm{~cm}$ langen Embryonen in die Bauchhöhle fand sich Wachstum von 1 bis $1,5 \mathrm{~mm}$ auf $0,5-1 \mathrm{~cm}$. Ein Teil der Stücke kann allerdings verschwinden. 
Nach 8 Tagen sind gewöhnlich in einer Knorpelhöhle 3-6 Zellen von Halbmondform, im Kontrolpräparat immer nur eine. Noch stärkere $\mathrm{Wu}$ cherung zeigt sich am 17. Tag, bis zu 28 Zellen in einem Hof der Grundsubstanz. Diese Vermehrung tritt herdförmig auf, scheint vornehmlich da vorhanden zu sein, wo die meisten Gefäße im einscheidenden Gewebe herantreten. Am 30. Tag zeigen sich bei ganz schrankenloser Vermehrung schon Übergänge zu Knochen- und Markraumbildung. Bei Einpflanzung von Stücken von $4 \mathrm{~cm}$ langen Embryonen findet sich schon 'am 12. Tag aus dem implantierten Epiphysenknorpel entstehend echte fötale Knochenbildung von den ersten Anfängen bis zur völligen Ausbildung. Noch vorgeschrittener zeigt sich dies am 20. u. 78 Tage. Knorpel von ausgetragenen Tieren zeigt bei Implantation in die vordere Angenkammer niemals Wachstum, er wird resorbiert, schrumpft oder bleibt im seltensten Fall stationär.

Nach Zahn zeigt nur fötaler Knorpel Wachstnmserscheinungen und zwar un so mehr, je gefäßreicher die Stelle der Aufpropfung ist. Auch dann beschränkt sich die Wucherung auf die peripheren Teile nach der Richtung des geringsten Widerstandes. Bei nicht fötalem Knorpel findet sich nie Proliferation, sondern derselbe verfällt der Verfettung und Auflösung. Das Wachstum des fötalen Knorpels geschieht im Innern durch Vermehrung der Grundsubstanz, an der Peripherie durch Wucherung der Knorpelzellen. Die Implantation erfolgte niemals in die Bauchhöhle, sondern unter die Haut, ins Auge oder in drüsige Organe.

Fischer dagegen hält eine so strikte Scheidung zwischen embryonalem und nicht embryonalem Knorpel nicht für möglich. Er fand auch bei Fötalknorpel das Wachstum nur auf einige Monate beschränkt, die schließlichen Veränderungen waren bei beiden Arten gleich. Er machte die Übertragung von Rippenknorpel von $1 / 2 \mathrm{Jahr}$ alten Hühnern in den Bartlappen von anderen Tieren gleicher Art und differenzierte die Versuchsanordnung dahin, daß er die Stücke entweder mit oder ohne Perichondrium übertrug, auch Knorpel von älteren Tieren wählte oder Knorpel plus Knochen nahm. Bei Übertragung ohne Perichondrium bestehen schon kurz nachher in den Randpartien Proliferationen, nach 6-8 Tagen finden sich 4 und mehr Zellen in einer Höhle, nach 2 Wochen sind viele Kapseln mit kleinen, rundlichen, Granulationszellen ähnlichen Gebilden erfüllt, in Ausstiilpungen der Kapsel zeigen sich Zellen eingelagert, die Grundsubstanz wird dadurch verdrängt, so resultiert schließlich ein ziemlich gleichartiges Granulationsgewebe. Dies alles gilt von der Randzone, im Innern sind noch die Anfänge mit allmählichen Übergängen zu 
beobachten, im Centrum noch ganz unveränderter Knorpel. Die Kapseln sind immer geschlossen. In der Grundsubstanz findet sich nie eine Zelle. An manchen Stellen bleiben die Proliferationen aus mit direktem Absterben der Knorpelzellen. Die Proliferationsherde haben im allgemeinen Keilform mit der Spitze nach innen, dazwischen sind unveränderte Knorpelpartien. Die Homogenität der Grundsubstanz verändert sich, es finden sich Linien- und Spaltsysteme, die nach Fischers Ansicht durch die Saftströmung bedingt sind. Auf der Verschiedenbeit der letzteren beruht auch die verschiedene Proliferationsintensität.

Je jünger der Knorpel, desto gleichmäßiger ist das Verbalten desselben. Die aus dem Knorpel entstehenden Granulationszellen gehen schließlich ohne scharfe Grenze in die des Mnttergewebes über. Erst nach 6-8 Wochen finden sich innerbalb des veränderten Knorpels Blutgefäße. Es resultiert also schließlich eine Netaplasie des Knorpels in junges Bindegewebe mit Fibroblasten. Kommt es durch ungenügende Ernährung zu partieller Knorpelnekrose, so wird dieser Teil demarkiert und unter Bildung von Riesenzellen eingeschmolzen.

Auch bei ganz oder teilweise erhaltenem Perichondrium kommt es zu einer allmählichen Umwandlung des Knorpels. Eine Persistenz obne Proliferation und Umwandlung des Knorpels findet sich nur bei Überpflanzung von Knorpel von 1:2-1 Jahr alten Tieren auf gleichaltrige Individuen.

Bei Transplantation von embryonalem Knorpel fand $F$ ischer in den Anfangsstadien das gleiche Verhalten wie Leopold und Zahn, die Weiterentwicklung aber erfolgte nach ihm mit normaler Gesetzmäßigkeit. Die Wachstumsvorgänge sind um so energischer, je weniger Weichteile der Knorpel enthält. Schließlich kommt es nach einigen Monaten zum Stillstand und dann zu den analogen Veränderungen wie am nicht embryonalen Knorpel.

Bei Überpflanzung von differentem Knorpel kommt es auch zu Proliferation, nach 3-4 Wochen zeigt sich körniger Zerfall mit schließlicher Bildung einer homogenen Masse.

Bei Implantation von menschlichem Knorpel nach dem Tode teils embryonal teils von Kindern findet sich auch Proliferation, selbst bei Übertragung $12 \mathrm{~h}$ nach dem Tode noch. Dabei treten die Kapseln durch Kanalsysteme miteinanderin Verbindung. Ich kann aus Fis chers Beschreibung nicht den Eindruck gewinuen, daß es sich um Veränderung der autochthonen Zellen handelt, glaube vielmehr, daß Zellimmigration mitspielt. Fis cher hält schließlich die Veränderungen bei Knorpelwunden, bei freien Gelenkkörpern, bei den Knorpelsequestern 
der chronischen Arthritis den Befunden bei der Überpflanzung für vollkommen analog.

Helferich-Enderlen fanden bei der Reimplantation des resecierten Intermediärknorpels beim Kaninchen, daß der größte Teil des implantierten Knorpels zu grunde geht, trotzdem in der Wucherungszone und in großblasigen Knorpel Mitosen zu sehen sind. Die Regeneration tritt größtenteils vom Perichondrium und von Teilen des Säulenknorpels aus auf.

Enderlen schildert die dabei erhobenen Befunde genauer. Anfänglich tritt eine Schädigung des Knorpels ein, die Degeneration beschränkt sich nicht auf die Zellen, sondern verändert auch die Grundsubstanz in ihrem Aussehen. Sie findet sich vornehmlich in den mittleren zentralen Teilen, doch auch sonst nocb inselweise, ausgesprochener in Säulen- und im großblasigen Knorpel als in der Wucherungszone. Daneben bestehen auch deutliche Zeichen progressiver Veränderung, Mitosen bis zum 30. Tag vorwiegend an den Rändern, also unter dem Einfluß 3 des Perichondriums, reichlicher als im nicht operierten Knorpel. Diese neugebildeten Zellen beteiligen sich aber nicht am Aufbau von Intercellularsubstanz, sondern verfallen teilweise wieder einer regressiven Veränderung, wie E. aus dem Auftreten von Sichelzellen in den Knorpelhöhlen schlielst. Von diesen wird auch bei meinen Befunden noch die Rede sein.

Der überlebende Knorpel ossificiert dann vom Rand her und zwar augenscheinlich durch Apposition, nicht durch Metaplasie. Erwähnen möchte ich noch, daß E. eine Höhenzunahme des operierten Knorpeis schon am 5. Tag findet, die er nur zum geringsten 'Teil auf Zellvermehrung zurückführen möchte, vielmehr auf Expansion und Quellung für die ersten Tage. Später spielt der mangelnde Abban eine Rofle.

Ollier spricht sich dahin aus, daß obne Perichondrium trans plantierter Knorpel nicht einwächst, daß der Gelenkknorpel der fettigen Degeneration verfällt. Das gleiche fand Tizzon $\mathrm{i}$ bei der Überbringung unter die Haut und in die serösen Höhlen. Neben der ausnahmslos eintretenden fettigen Degeneration besteht immer Zerstörung durch Zelleinwanderung. Nach seiner Ansicht kann nur die Synovia den Knorpel ernähren.

Auch Pru dd en konstatierte, daß der überlebende Knorpel in wenigen Wochen resorbiert wird. Nur in einem Falle fand er eine geringe Wucherung von Knorpelzellen.

Saltykow, Mangold und $\mathrm{Henle}$ sprechen eine regenerative Tätigkeit ausschließlich dem Perichondrium zu, nur im Influenzbe- 
reich desselben bleibt der Knorpel am Leben sonst ist er entweder ruhend (Henle) oder er geht zu grunde. Lubarsch erwähnt schlieblich bei der experimentellen Kritik der Grawitzschen Lehre, daß bei Transplantation von perichondriumfreien Knorpelstiickchen in den Lymphsack des Frosches keine Wanderzellen eindringen wegen des Mangels an Porosität. Solche Stückchen werden überhaupt kaum organisiert. Ganz anders ist das Bild, wenn vor dem Einbringen der Knorpel durch Nadel- oder Messerstiche mit zablreichen Löchern versehen wird. Dann wandern überall Leukcyten ein.

Die Ansichten sind sich also wiedersprechend genug; ihre Differenz kumuliert sich bei der Frage der Entstehung der freien Gelenkkörper, eine Frage, die hier unmöglich in ihrem ganzen Umfang angeschnitten werden kann, sondern nur insoweit berïhrt werden soll als der Gelenkknorpel selbst beteiligt ist. Ich kann deshalb auch auf den grundlegenden Streit zwischen Barth und König - ob traumatische Entstehung oder Osteochondritis dissuans - nicht eingehen sondern beschränke mich auf die Mitteilung der Befunde.

Die Litteratur über die Frage ist bei $\mathrm{Barth}$ zusammengestellt, wo auch die anatomischen Resultate nachgelesen werden können. Uns interessieren hier an erster Stelle die experimentellen Ergebnisse B arth $\mathbf{s}$ an Hunden über das Verhalten frei im Gelenk befindlicher Teile der Knorpeloberfläche. Im Gegensatz zu den mit aus der Kontinuität gelösten Knochenteilen an der Unterfläche des Knorpelslücks, die sehr rasch absterben, zeigt der Knorpel eine große Lebensfähigkeit. Es findet sich nur eine ganz schmale Randnekrose, dabei zeigt sich in den anderen Schichten keine Unwandlung der ruhenden Knorpelzellen in jugendliche Formen. Die bindegewebige Metaplasie, wie sie narh $\mathrm{F}$ is cher so universell bei der Überpflanzung eintritt, beobachtete Barth niemals, er leugnet die Möglichkeit einer solchen Umwandlung nicht, glaubt aber nur an ein sehr bescbränktes Auftreten derselben. B. sah niemals Wucherung der Knorpelelemente an der Grenze des einscheidenden Gewebes, dieselbe war immer sehr scharf. Die Vitalität des Knorpels ist jedoch nur eine beschränkte, alle künstlich erzeugten Gelenkkörper verfallen schließlich der Resorption. Es treten degenerative Vcränderungen auf und trotz der anfänglich massenhaften Neubildung an der Verwachsungsstelle, wobei auch embryonaler Faserknorpel entstehen kann, zeigen massenhafte Riesenzellen nach 6 Wochen und das Eindringen von Bindegewebszapfen von Mark und Oberfläche her, daß eine Resorption eingeleitet wird, die aber niemals durch Auflösung der Knorpelsubstanz in Synovia bewirkt wird, sondern immer eine organische ist. Eine Auflösung kann schon 
deshalb nicht erfolgen, weil die Gelenkkörper alle petrificieren und zwar findet sich diese Verkalkung am meisten bei den ganz freien Körpern, während sie bei !breiter Verwachsung fehlt und bei zarter stielförmiger Verbindung mit der Gelenkkapsel mehr oder weniger reichlich ist.

Im Gegensatz zu dieser nur temporären Vitalität des Knorpels bei künstlich erzeugten Gelenkkörpern stehen seine Befunde bei den corpora libera des Menschen. Auch hier fand er zwar, daß der eigenartige Bau des menschlichen Gelenkknorpels im postfötalen Leben niemals wiederholt, niemals neugebildet wird, jedoch konstatierte er immer das Vorhandensein von embryonalem Faserknorpel, gebildet vom Einscheidung'sgewebe der Verwachsungsstelle. In einem Falle, $1_{1 / 2}$ Monate alt, fanden sich breite Degenerationsherde im Knorpel mit starker Verkalkung der basalen Schichten desselben besonders am Bruchrand, dagegen zeigte sich in einem 3 Monate alten der Knorpel absolut intakt, ebenso bei einem 5 Jabre zurückdatierenden Fall.

In einem andern Fall von gleicher Dauer fand eine ausgesprochene regressive Metamorphose des Knorpels statt, der ganze Knorpel war stark verkalkt und kernlos, nur im Bereich des mitausgesprengten Ansatzes eines Seitenbands fand sich Wucherung von Knorpelzellen mit massenhaftem Auftreten von Tochterzellen und fehlender Verkalkung. In den andern 6 Fällen dagegen, die er untersuchte, bestand eine wie schon erwähnt, bis auf die Dauer von 5 Jahren sich erstreckende Tenacität des Knorpels mit starker Verkalkungstendenz ohne Auftreten von Riesenzellen, ohne Eindringen von Granulationszapfen in denselben, auch eine bindegewebige Metaplasie des Gelenkknorpels konnte nicht beobachtet werden, höchstens in den oberflächlichsten Schichten.

A. Schmitt, der mit gleicher Versucbsanordnung arbeitete und seine Ergebnisse kurz auf dem Chirurgenkongreß 1896 berichtete allerdings stellte er seine Versuche an Kaninchen, nicht an Hunden an -- konstatierte, wie Barth eine starke Hinfälligkeit des mit überpflanzten Knochens, fand dagegen im Bereich des Knorpels ganz andere Verhältnisse als Barth. Die äußeren ungeordneten Knorpelschichten zeigen nach ihm eine Tendenz zum Wachstum, sie wuchern und umwachsen in bindegewebiger Metaplasie die Knochenseite des überpflanzten Stückehens und können schließlich Knochen bilden, während der innere, großblasige Knorpel sich wie der Knochen verhält, d. h. rasch zu grunde geht. Dies stimmt gar nicht mit meinen Befunden. Auch bei menschlichen Gelenkmäusen fand er zum Unterschied von Ba rth Knochenbildung vom äußeren indifferenten Knorpel aus. 
Die Differenzpunkte gegen Barth und, wie ich vorwegnehmen nöehte, gegen meine Befunde sind also sehr groß.

Die letzten Untersuchungen über diesen Gegenstand stammen ron Börner. Er fand bei menschlichen Gelenkmäusen inmer Nekrose des Knorpels, kenntlich durch Pyknose, Vakuolenbildung, Verlust der Kapsel, Schrumpfung und Erweiterung der Kapselräume. In den vorgeschrittenen Fällen besteht sogar faserige Degeneration der Grundsubstanz. Er bält eine anfänglich in den ersten Stadien vorhandene gute Kernfärbung der Knorpelzellen nicht für ein Zeichen der Vitalität, weil er auch bei Überpflanzung von totem Knorpel von Leichen in die Bauchhöhle von Kaninchen noch nach 14 Tagen in der Peripherie gute Kernfärbung fand bei $1,5 \mathrm{ccm}$ großen Stiicken.

Auch diese Untersuchungen an experimentell und traumatisch entstandenen Gelenkkörpern bringen also noch keine Klarheit, noch keine Übereinstimmung der Befunde über die Frage der Vitalität, der Regenerationsfähigkeit des Knorpels, besonders des Gelenkknorpels.

Bevor ich nun auf meine Befunde und deren Ergebnisse eingehe, möchte ich in kurzen Zügen die Versuchsanordnung schildern, die ich bei meinen Arbeiten obwalten ließ.

Ich experimentierte an Kaninchen und zwar fast ausschließlich an jungen Tieren unter $2000 \mathrm{~g}$ Gewicht. Das linke Kniegelenk wurde durch subpatellaren Querschnitt eröffnet; aus der Konvexität jedes Condylus femoris und der Fossa intercondyloidea ant. je ein möglichst flaches Stück mit dem Messer ausgeschält, in eine sterile Schale verbracht und nach Eröffnung der Bauchböhle an umschriebener Stelle nach verschiedenen Richtungen in dieselbe eingeschoben. Die Wunden heilten fast ausnahmslos per primata, die Untersuchung erfolgte 6 , $16,24,41,48$ Stunden, 3, 4, 5, 6, 7, 10, 11, 12, 14, 16, 19, 22, 25, $30,32,35,40,45,50,60,70,80$ Tage nach dem ersten Eingriff. Die Implantation war zum großen Teil an der Innenseite der Laparotomiewand erfolgt besonders in den ersten Stadien, nächstdem am häufigsten im Omentum maius und im Mesenterium des Dünndarms, seltener auf der Darmoberfläche, nur ausnahmsweise an der hinteren Parietalserosa. Manchmal, besonders in den spätern Stadien fanden sich die Stiickchen auch anscheinend frei in Bauchfellraum. Die Gröle derselben betrug gewöhnlich ca. $5 \mathrm{~mm}$ in der Länge, ca $3 \mathrm{~mm}$ im Maximum in der Breite. Eine entzündliche Reaktion in Bereich der Verwachsung wurde niemals gefunden, auch wenn die Muskelwunde unter der reaktionslos verheilten Hautwunde Eiterung zeigte. Die Fixation der mit dem sekundären Mutterboden entnommenen Stückchen erfolgte an jedem Stadium zum Teil in Sublimat, zum Teil 
in Alkohol 96 Proz., die Einbettung anfangs in Paraffin nach vorheriger Behandlung mit Cedernöl, später nach Entkalkung der zum Teil petrifizierten Stücke in Celloidin. Die Färbung erfolgte mit Hämatoxylin - Weigert-Erythrosin, van Gieson, Bleu de Lyon, Fibrin - Weigert, polychromem Methylenblau, Pyronin- Pappenheim; Orcein-UnnaTänzer und mit der neuen Glykogenreaktion nach Best. Die Orceinfärbung gewährte besonders für die späteren Stadien in der Differenzierung der Grundsubstanz des Knorpels gegen das osteoide, an gelagerte Gewebe ein sehr anschauliches und instruktives Bild. Die Kontrastfärbung der Zellen gegen die Grundsubstanz, die Moll beschreibt (Zellen blauviolett, Grundsubstanz rötlich), konnte ich allerdings nicht erzielen. Die Orceinfärbung bewährte sich auch sehr gut für die Kenntlichmachung des Plasmaleibes der Knorpelzelle gegen die Grundsubstanz. Professor As ch off machte mich auf diesen, von ihm schon öfters konsiatierten Umstand aufmerksam. Die Färbung mit polychromem Methylenblau wurde $1 \mathrm{~h}$ lang vorgenommen und nach kurzem Abspülen mit Wasser mit stark verdünntem Glycerinäther unter Kontrolle mit dem Mikroskop differenziert und rasch durch Alkohol in Origanumöl übcrgeführt. Sie bewährte sich besonders in den ersten Stadien für die feineren Veränderungen des Protoplasmas der Knorpelzellen, das immer eine zart rosa Färbung annahm. Eine Differenzierung der Knorpelzellen gegen die Bindegewebszellen ließ sich mit der Pappenheimschen Methode (Pyronin 1 h lang bei $37 \%$, Differenzierung mit Wasser) nicht erzielen. Sie bot gegenüber dem Methylenblau keine wesentlichen Vorteile. Die Glykogenreaktion endlich wurde immer angestellt in der Erwartung, daß ihr negativer oder positiver Ausfall einen Anbaltspunkt geben würde für die Vitalität der Zellen. Kurz' vorweggenommen sei, dab sie überall bis zuletzt, wenn auch in verschiedener Intensität positiv ausfiel. Ich hielt mich dabei ganz genau an die letzten Angaben Bests. Das Glykogen fand sich teils in Form von Halbmonden an der der Gelenkoberfläche abgewendeten Seite der Knorpelzellen, oder als diffuse feine Plasmakörnelung, manchmal auch in mehr oder weniger großen Schollen. Bisweilen war es auch frei im Gewebssaft anzutreffen, ebenso wie Bestes bei der Entzïndung und Eiterung konstatieren konnte. Auch in den Muskelfasern konnte ich es nachweisen. Wie Best fand ich, daB wässerige Fixationsmittel, auch die Entkalkung auf den Nachweis desselben nicht nachteilig einwirken. Im zweiten Teil wird bei der Schilderung des Verhaltens der Knorpeldefekte noch genauer über das Glykogen zu sprechen sein, anführen möchte ich jetzt nur, daß dort wie auch in den überpflanzten Stückchen sebr oft der Glykogengehalt 
ein ganz immenser war, viel größer als im wuchernden Knorpel, so daß ich mit Best das Vorhandensein von viel Glykogen in den Knorpelzellen als ein Zeichen erhöhter Aktivität derselben ansprechen möchte. Damit stimmt auch, daß es sich sehr oft am häufigsten in den Scbichten fand, wo Mitosen der Knorpelzellen zu beobachten sind (6b). Ich setze mich dabei allerdings in Widerspruch mit einer Reihe von Forschern (siehe die letzte Zusammenstellung von Reich in den Beiträgen zur klin. Chir.), die das Vorhandensein an Glykogen besonders in den polynucleären Leukocyten für ein Zeichen von Zelldegeneration ansehen. Ich konnte Glykogen allerdings auch in karyolytisch veränderten Zellen nachweisen.

Ich wende mich nunmebr zur Schilderung meiner Befunde und bemerke zum leichteren Verständnis, daß ich unter Knorpeloberfläche immer den ehemals gegen das Gelenkinnere gerichteten Knorpelteil verstehe.

1. 6 Stunden nach Implantation:

Alle 3 Stückchen zusammengebacken, dem Dickdarm in der Vitte aufliegend; ganz zarte Verklebungen mit der Umgebung; Fixation in Alkohol 96 Proz.

Mikroskopisehes Bild:

Drei Knorpelstiickchen liegen flach der Darmwand an, zwei mit der freien Seite dem Darm abgekehrt, das dritte mit der Gelenkoberfläche gegen die Darmserosa sehend. Besonders in den oberflächlichen Schichten sieht man leere Knorpelhöhlen, in den tieferen weniger. Die erhaltenen Zellen zeigen keine auffallende Veränderung der Form, haben sich höchstens etwas vom Rand der Knorpelhöhle retrahiert. Das Zellprotoplasma ist iuberall deutlich ausgesprochen, der Kern stark chromatinhaltig, die Knorpel grundsubstanz färbt sich, nicht mit Erythrosin. Die Serosadeckzellen sind noch ganz passiv, zwischen ihnen und dem Knorpel ein zungenförmiger Bluterguß, der schon ebenso wie der Zwischenraum zwischen den einzelnen Stückchen ziemlich viel Leukocyten entbält. In den oberflächlich gelegenen Knorpelstückchen scheint die Kernfärbung noch besser erhalten zu sein, als in dem unmittelbar dem Darm anliegenden (geringere Saftdurchströmung). Mit Immersion sieht man bei Orceinfärbung den Protoplasinakörper dent. lich granuliert, mit scharfen Konturen, die Zellkerne sind überall bläschenförmig in den Deckschichten kompakter, als in den tiefen. Diese mehr jugendlichen Formen fehlen neben dem Defekt im Knorpel (siehe II. 1). In einzelnen kleinsten, artifiziellen Spalten besteht Leukocyteneinwanderung.

2. 16 Stunden nach Implant.

Komplikation durch Darmverletzung, die mit doppelreihiger Naht versorgt wird.

a) Implant. am Darm, am unteren Ende der Darmnaht.

Der Knorpel ist in eine reich von Leukocyten durchsetzte Membran eingelagert, die Knorpeloberfläche gegen den Darm gerichtet. Die Leukocyten erstrecken sich nirgends in den Knorpel hinein, obwohl leere Knorpelhöhlen nur durch wenig Grundsubstanz vou ihrem Wall getrennt sind. 
Nur im Bereich des verkalkten Basalknorpels filıden sich einzelue Hufeisenkerne in einigen Knorpelhöhlen, welche aber augenscheinlich artifiziell mit den überpflanzten Markräumen kommunizieren. Die Grundsubstanz des Knorpels ist immer scharf abgesetzt, die Zellen der oberflächlichen Schichten sind nicht verändert und bestehen aus schmalen Spindeln mit der Achse parallel zur Gelenkfläche. In den mittleren Sehichten findet sich Karyolysis, man sieht rosa Plasmamassen in Innern der Knorpelhöhlen mit unregelmäßigen Chromatinkrümeln, in den tiefen Schichten finden sich teils leere Höhlen, teils geschrumpfte Zellen mit Vakuolenbildung im Protoplasma, aber auch riele sehr gut erhaltene Zellen.

b) Implant. im großen Netz.

Hier erscheint der Knorpel noch besser erhalten und ist in ein zellig verdicktes Netz mit starker Leukocyteninfiltration eingescheidet. Die Knorpelgrundsubstanz ist überall homogen ohne eine Spur von Auffaserung oder Lüickenbildung. Im allgemeinen lassen sich zwei Arten von Knorpelzellen unterscheiden: solche mit großem, bläschenförmigem Kern, fein granuliertem Zellleib - mit Orcein am besten kenntlich - und deutlich abgesetzter Kapsel. Zweitens solche mit kleinem, kompaktem Arm und geschrumpftem Zelileib. Diese beiden Arten sind aber nicht schichtförmig geschieden, sondern die zweiten finden sich mehr in dem mittleren Knorpelteil mit dem größten Dickendurchnesser, die ersten ror allem in den seitlichen Ausläufern. Doch finden sich auch hier einzelne inselförmige Bezirke mit leeren Knorpelhöhlen. In einzelnen Höhlen der oberflächlichen Schichten besteht staubförmiger Zerfall des Chromatins, manchmal ist daneben noch ein kompakter, geschrumpfter Kern zu erkennen. Für Zerfallsprodukte von Leukocyten möchte ich die kleinsten Krümel neben dem Kern nicht halten, obwohl man in einzelnen, leeren Knorpelhöhlen im äußersten, zugespitzten Teil des Knorpels nicht nur einzelne, sondern mehrere gut erhaltene Lerrkocyten exkennen kann. In mancheu Schnitten erhält man den Eindruck, besonders bei Färbung der Grundsubstanz mit Bleu de Lyon, daß der gegen den Knorpelrand gerichtete, dicht gedrängte Leukocytenwall den sonst scharf abgesetzten Rand der Grundsubstanz anfirit; es fehlt dann die scharfe Kontur desselben. Nur auf diese Weise ist auch die Einwanderung in leere Knorpelhöhlen zu erklären. Diese müssen zuerst eröffnet sein. Ein Vordringen durch die Grundsubstanz wird niemals beobachtet.

3. 24 Stunden nach Implant.

a)Adhärenz am Dickdarm. Alkoholfixation. Knorpel liegt mit der Kunochenseite der Darmwand an und ist in ein feines Fibrinhäutchen eingekapselt. Die Grundsubstanz ist gleichmäßig homogen, nicht aufgefasert, leicht rosa gefärbt. In einzelnen Abschnitten zahlireiche leere Knorpelhöhlen, am wenigsten in den zugespitzten Randpartien. Die Kerne sind gerade hier sehr gut gefärbt, die Zeilgrenzen sebr deutlich. Im Bereich der leeren Knorpelhöhlen sind die noch erhaltenen Kerne pyknotisch, Zellleib sehr undeutlich und von der Wand retrahiert. Leere Knorpelhöhlen besonders im Bereich des verkaikten Knorpels. Der Knorpel liegt unmittelbar der Serosa auf, nur 'an einzelnen Stellen trennt ihn eine schmale Leukocytenschicht. Nirgends am Rand dringen diese in die Grundsubstanz ein; eine Schichtung des Knorpels nach dem Zellcharakter ist nicht vorhanden; abgeplattete Zellen finden sich nur ganz spärlich in den obersten nach außen gekehrten Schichten. 
Bei Färbung nach Unna-Tänzer erkennt man das Verhaiten der Serosa sehr schön. An den Deckzellen ist noch keine Reaktion nachzuweisen; sie bilden über einer Lage elastischer Fasern eine schmale, ein bis mehrreihige Zellschicht, dann kommt eine homogene Schicht, angenscheinljch Fibrin mit einzelnen Leukoeyten. Die Knorpelkonturen sind ganz scharf; eine Resorption der Grundsubstanz durch den Leukocytenwall wie bei $2 \mathrm{~b}$ absolut nicht festzustellen. Die Zellumrisse sind sehr deutlich, vollkommen der Knorpelhöble entsprechend, ebenso die Kernkonturen. Im Bereich der kompakten Kernfärbung ist auch der Zellkörper ganz eng geschrumpft und der gröBte Teil der Höhle leer. Längs einer artifiziellen Fissur sieht man einige Leukocyten und Phagocythen, aber nur im Bereich des Spaltes vorgedrungen. An der einen äußersten Spitze sind zwischen den Knorpelkernen abenteuerliche Kernformen von Wanderzellen zu erkennen. Bei van Gieson zeigen sie sich im Bereich der Knorpelhöhlen liegend; hier sieht man aber auch das Offenstehen dieser Höhlen gegen die Darmwand.

Mit Pyronin.Pappenheim zeigen sich die Kerne der Phagocyten und Leukocyten viel stärker grün gefärbt, als die Knorpelkerne, so daß die letzteren ganz genau davon zu unterscheiden sind; auch fehlt ihneu der rote Nucleolus, der sich sonst in allen Zellen findet.

b) Sublimatfixation eines ebenfalls am Dickdarm adhärenten Knorpels bietet genau denselben Befund. Hier ist der Ansatz eines Lig. cruciatum mit transplantiert. Sehr auffallend ist bei Färbung mit polychromem Methylenblau der aussehließliche Befund von sich erholenden Kapselformen im Knorpel, direkt neben dem teils ganz kernlosen, teils nur pyknotische Kerne zeigenden Ligament.

4. 41 Stunden nach Implant.

2 Knorpelstücke der Laparotomiewunde innen adhärent. Einscheidung bildet eine verschieden dicke Schicht von flachen, platten Zellen. Die Knorpelgrundsubstanz ist gleichmäßig homogen, ganz schwach rosa gefärbt; eine Einwanderung findet nirgends statt. Knorpelzellen: Kerne zum größten Teil ganz kompakt und sehr stark gefärbt. Protoplasmakörper von der Wand der Höhle stark retrahiert und nicht mehr so fein granuliert. In einzelnen Regionen Bezirke von leeren Knorpelhöhlen; große, bläschenförmige Knorpelzellkerne finden sich nur in den tiefen basalen Schichten. Mit polychromem Methylenblau ist in den mehr zentral gelegenen Teilen noch ein deutlich mit Ausläufern versehener Protoplasmakörper vou rötlicher Farbe um den ganz blaßblau gefärbten Kern nachzuweisen; er steht durch ein feines Netzwerk mit der Wand der Knorpelhöhle in Verbindung. Die regressiv veränderten Zellen zeigen einen tiefblauen Kern mit violetter Grundsubstanz. In den der Parietalserosa unmittelbar anliegenden Schichten finden sich in einem großen Teil der Knorpelhöhlen Niederschläge von feinen und gröberen Chromatinklumpen; diese verschwinden da, wo die großen fibroblastenähnlichen Zellen auftreten; am Rand finden sich nur die pyknotischen Zellen.

5. 48 Stunden nach Implant. fixation.

Ein Stückchen der Bauchwunde innen breit adhärent; Alkohol-

a) Die Einscheidung bildet größtenteils eine einfache Lage von Deckzellen mit Leukocyteninfiltration. Der Befund hat sich wenig geändert, 
auch hier wurde wieder ein Stlick Ligament oder Kapselansatz mit übertragen, und unterseheidet sich dies durch ausgedehnte Chromatolyse von dem knorpeligen 'Teil. Die mit Methylenblau und Pyronin gegenüber den Knorpelkernen sehr lebhaft gefärbten Wanderzellen infiltrieren das fibröse Gewebe, dringen aber nicht in die Knochengrundsubstanz ein, deren Zellen fast alle vollsaftige Kapselformen mit selur fein granuliertem Zellleib zeigen. Sogar eine Mitose ist hier am Knorpelrand nachzuweisen. Daneben finden sich auch noch leere Höhlen; auch lassen einzelne wieder erholte Formen bröekeligen Verfall des Zellleibs, Verlust der Kernmembran, Aufhellung des Chromatingerüstes usw. erkennen. Der größte Leukocytenandrang besteht an der dem Darm abgewendeten basalen Knorpelseite. Hier wird die Grundsubstanz wieder direkt abgenagt.

b) 2 Stückchen am Mesenterialansatz des Dünndarms adhärent. Sublimatfixation. Die Knorpelstïckchen sind vom Mesenterium eingescheidet und zunächst von mit Blutkörperchen durchsetzten Fibrinmassen umgeben. Das ganze Mesenterium ist sehr blutreich, die Bindegewebszellen sehr groß und saftreich, augenscheinlich in lebhafter Wucherung begriffen. Dem Knorpel liegt direkt auf teils eine Schicht von amorphen, stark rot gefärbten Schollen und Bündeln, die in verschiedener Stärke von weißen und roten Blutkörperchen durchsetzt sind, teils das fibrilläre Mesenterialgewebe mit und ohne Blutkörperchen und mit und ohne eine einfache Lage von kubischen Zellen. Der Knorpel erscheint ganz scharfrandig, obne irgend eine Spur ron Zelleinwanderung; die gegen den Darm gerichtete Spitze zeigt in den superficiellen Schichten eine starke Schrumpfung und Retraktion der platten Knorpelzellen, deren Chromatin nur noch als feinste Körnchen nachzuweisen ist, teils auch schon ganz verschwunden ist. Ganz am Rand ist noch eine größere Gruppe von großblasigen Knorpelzellen vorhanden, deren Kerne größer und saftiger erscheinen. In einer Knorpelhöhle findet sich daneben noch eine Lalbmondförmig gekrümmte Spindelzelle. Dann zeigt sich in den basalen Schichten eine lebhafte Zellwucherung innerhalb der Knnorpelhöhlen; dieselben sind vollgepreßt vou großen, saftigen Zellen; hier sind auch zwei deutliche Knorpelmitosen sichtbar, ein Diaster und Monaster, ebenso an die Wand gedrängte, kompakt gefärbte Sichelformen. Mehr im Centrum, den Knochenteilen gegenüber, zeigen sich in einer ganz isolierten Knorpelhöhle 2 deutliche Spindelzellen; dieselben müssen unngewandelt sein, können nicht eingewandert sein. Solche Stellen finden sich noch mehrfach, auch Übergänge zu Formen mit noch entschieden bläschenförmigem Kern. Gegen die andere Spitze zu treten dann wieder Karyolysen auf, doch lassen sich auch hier vollsaftige Formen bis in die äußerste Spitze verfolgen. Die Wucherung innerhalb der Knochenhöhlen wird schließlich so enorm, daß der Konnex der Grundsubstanz gesprengt wird und eine innige Mischung mit den Mesenterialzellen eintritt, wobei auch die Grundsubstanz des Knorpels direkt in die Fibrillen überzugehen scheint.

6. 3 Tage nach Implant.

Darmadhärenz. Alkoholfixation.

Die Einscheidung wird außen ron einer dicken, teilweise homogen amorphen Schicht mit mäßigem Zellgehalt, innen von einer nicht sehr dicken Zelischicht von großen, ovalen und kubischen Zellen und spärlichen Fibrillen gebildet. Die Knorpelzellen sind nicht so vollsaftig, nicht so gut konser- 
viert. nicht so zahlreich, wie bei $5 \mathrm{~b}$; starke Schrumpfung der platten Zellen. Karyolyse der großblasigen, Auftreten von leeren Knorpelhöhlen oder mit Detritus gefüllten. Auch hier Abplattung und Übergang in Spindelformen, die oft zu mehreren in einer Höhle zu treffen sind. Grundsubstanzkonturen überall scharf; keine Einwanderungen. Die zugespitzte Randpartie zeigt degenerative Erscheinungen nur an den basalen Teilen; die superfiziellen Zellen sind gut gefärbt. Die großblasigen Formen zeigen in vielen Schnitten starke Vakuolenbildung; solche ist auch in den spindeligen Formen an beiden Polen zu beobachten. Dabei sind die Kerne sehr gut ausgebildet ohne Degenerationszeichen.

b) Adhärenz an der Laparotomiewunde. Sublimatfixation.

3 Knorpelstückchen sitzen, sich dachziegelförmig deckend und mit der Knochenfläche nach der Parietalserosa gerichtet, der Wunde auf und sind ron einer ganz feinen, zelligen Membran eingeschlossen. Das unterste ist rom Peritoneum selbst durch einen feinen Bluterguß getrennt. Die Peritonialendothelien sind hier als solche nicht mehr zu erkennen; sie gehen vielmehr von einem Rand her direkt in Spindelzellen über; ob sie auch die deckende Membran liefern, vermag ich nicht zu sagen. Die groBblasigen Knorpelzellen verhalten sich auch in den verkalkten Teilen genau so wie bei $5 \mathrm{~b}$; auch in den oberflächlichen Schichten, unter den platten Zellen sieht man fast nur kernhaltige Zellen, die am spitzen Ende des ersten Stïcks stark gewuchert sind, Mitosen zeigen und einen fibrillären Zerfall der Grundsubstanz bewirken. Also besteht hier keine Differenz zwischen den oberflächlichen und tiefen Knolpelschichten. Im Leib der großen Zellen sind manchmal Vaknolen zu sehen, oft so umfangreich, daß die Zellen zum Platzen gefüllt sind. Glykogen findet sich reichlich in fast allen Knorpelzellen, auch in der oberflächlichen Schicht, hier im Bereich der Mitosen sogar auffällig.

Auch in den ruhenden Zelien in der Verkalkungszone findet es sich, ebenso in den Zellen mit den großen Vakuolen, wie anch sonst, entweder schalenförmig oder als diffuse, staubförmige Körnelung oder als isolierte Schollen. In den basalsten Lagen ist Glykogen trotz deutlichster Kernform niemals zu finden.

7. 4 Tage nach Implant.

a) Adhärenz am Netz: Alkoholfixation.

Knorpel ist direkt eingeschlossen ron einer dicken Schicht Fibroblasten, untermiseht miteinigen Leukocyten. Der Knorpel ist ganz im Beginn getroffen, die Zellen zum T'eil vom Charakter junger, saftiger Zellen, zum Teil finden sich auch ausgedehnte Karyolysen, besonders in der Basalzone. Die oberflächlichsten Schichten des Knorpels bestehen bei Pyroninfärbung aus ganz schmalen Spindelzellen mit tiefrotem Plasmaleib; der Kern ist dabei noch nicht kompakt gefärbt. Diese Spindeln sind oft schon langgestreckt, aber von den Zellen des Granulationsgewebes deutlich different. Die Grundsubstanz erscheint dabei noch ganz homogen, während das einscheidende Netzgewebe einen ganz feinen retikulären Charakter zeigt. Dann kommt unter allmählichem Übergang die Schicht der großen, polygonalen Zellen mit Mitosen. Die tiefen Schichten des Knorpels sind größtenteils kernlos; man sieht in den Knorpelhöhlen noch nogefärbte Schollen und Krümel. In anderen Schnitten erscheinen auch schöne Kapselzellen. Der. Unterschied 
zwischen toten und lebenden Zellen ist ganz scharf ausgesprochen, eine allmähliche Umwandlung findet nicht statt. Später sieht man an der Stelle eines Kapselansatzes zwischen den Knorpelkernen auch langgestreckte Kerne, senkrecht zur Oberfläche des Knorpels auftreten, die bisher nicht zu beobachten waren. Dieselben müssen, da sie Einschnürungen zeigen, als Kerne von Wanderzellen angesprochen werden.

b) Ein Knorpelstückchen innen der Laparotorniewunde adhärent. Sublimatfixation.

Der Knorpel ist mit der Knochenfläche nach innen gegen die Bauchhöhle gerichtet. Das Endothel, das auf kurze Entfernung von der Implantation noch einschichtig, zeigt in unmittelbarer Nähe mehrere Schichten und schiebt sich unter starker Vermehrung und Leukocytenbeimengung über den Knorpel weg und nur an den Spitzen unter ihn hinein. Hier liegt die stark aufgelockerte und ron Leukocyten durchsetzte Fascie und perimuskulöses Gewebe, das von der Knorpeloberfläche durch einen Hohlraum getrennt ist, der teils von geronnener Flüssigkeit, teils von amorphen, ungefärbten Massen ausgefüllt ist, die spärlich von roten Blutkörperchen und von andern Zellen verschiedener Herkunft durchsetzt sind. Die Knorpelgrenze ist hier haarscharf zu erkennen. Der Hohlraum entsteht durch Aufbiegung des Knorpels in der Mitte, so daß er gegen die Bauchhöhle konvex ist. Der verkalkte Teil des Knorpels ist ganz kernlos. Hier kann man nun deutlich das Eindringen vornehmlich von Leukocyten verfolgen, nur vereinzelt von großen Wanderzellen, so daß einzelne Knorpelhöhlen und zwar nicht nur dem Endothelbelag anliegend, von den kleinen, runden Kernen der polynukleären Leukocyten erfüllt sind. Es können dies nicht Pyknosen der Knorpelkerne sein, da sie sonst nirgends sich finden und in Knorpel selbst ron degenerativen Veränderungen nur Karyolysen beobachtet werden.

Sonst finden sich nur vollsaftige Knorpelzellen, die an einzelnen Stellen bis zum Endothel reichen und hier vereinzeit unter Verlust der Kapsel in melr spindelige Formen übergehen. Hier sieht man ihnen auch noch abenteuerlich geformte, kompakte Kerne eingewanderter Zellformen beigemengt. Die Grundsubstanz des Knorpels ist dabei noch ganz kompakt und gerade an dieser Stelle sehr scharf gegen den Endothelbelag abgegrenzt. Ein Übergang der Knorpelzellen nach außen findet jedenfalls nicht statt. Der andere Teil des Knorpels ist ausschließlich von gauz jungen vollsaftigen Zellen mit großem Kern, dentlichem Plasmaleib und schöner Kapsel ausgefüllt, die bis zn fünf an Zahl in einer Knorpelhöble auftreten. Hier besteht also sicher aktive Wucherung der Knorpelzellen. Im Plasmaleib sind häufig Vakuolen und dem Kern radiär aufsitzende, stark lichtbrechende, große Körner (Glykogen?). Diese jungen Zellen erstrecken sich bis ganz an die Oberfläche des Knorpels, so daß hier gar keine spindeligen Formen zu erkennen sind; solche finden sich nur in den aufgerollten Endspitzen des Knorpels, aber immer neben den jungen Formen.

In einem andern Schnitt erkennt man in einem ganz kleinen, durch eine traumatische Fissur fast ganz abgesetzten und von einem dichten Wall von Bildungszellen umgebenen Knorpelstückchen im Centrum noch sich erholende Kapselzellen; die peripheren sind zugrunde gegangen, wandeln sich jedenfalls nicht in Fibroblasten um. Glykogen findet sich hier auffallend 
spärlich; nur an einzelnen Stellen ganz schmale Halbmonde und zwar nicht nur in den Kapselzellen, sondern auch in karyolytisch veränderten und in Leukocyten.

S. 5 Tage nach Implant.

2 Knorpelstückchen sitzen innen der Bauchwunde auf, teilweise in ein großes Fibringerinnsel hineinragend, zum Teil in einer drei bis vierschichtigen Zelllage eingescheidet. Gegen die Banchhaut zu schließt ein dünnfibrilläres Gewebe ab. Die Grundsubstanz ist homogen, die Konturen überall scharf. Knorpelzellen verhalten sich wie bei $6 \mathrm{a}$, wie dort in keiner Knorpelhöhle mehr als 6 Zellen; es fehlt die Wucherung, die bei 5 a so auffällig war. In den superfiziellen Lagen gegen die Bauchhöhle gerichtet zeigt sich keine Kernfärbung mehr. Zellspindel selbst ist noch gut konserviert, das Chromatin dagegen fast ganz auscrelaugt. Die basalen Zellen gegen die Verkalkungszone hin sind gut konturiert und zeigen normalen Kern, ganz zum Unterschied von $7 \mathrm{~b}$, wo die basalen Teile fast ganz kernlos waren.

9. 6 Tage nach Implant.

a) Alkoholfixation; Knorpel in großes Netz eingehüllt.

Knorpelzellen sind alle vorziiglich erhalten. Nur wenige leere Knorpelhöblen. Der Zellkörper hat sich fast nie von der Wand der Höhle retrahiert, zum Unterschied von 6 a. Dem Knorpel liegen junge Bildungszellen aus dem Mesenterium direkt an. Eine vermehrte Füllung von Knorpelhöhlen ist nicht zu beobachten.

b) Sublimatfixation. Knorpel der Laparotomiewunde aufsitzend und in ihr angewachsenes Omentum eingehüllt.

Der Knorpel zeigt allseitig scharfe Konturen und liegt dem weitmaschigen, fibrillären Netzgewebe überall dicht an; letzteres enthält besonders auf der Oberflächenseite des linorpels zahlreiche feinste Gefäße, die bis dicht an den Knorpel heranreichen. Eine fibrilläre Veränderung der Knorpelgrundsubstanz ist nirgends $\mathrm{zu}$ sehen. Mit Immersion findet man nur großblasige Knorpelzellen mit rundem bis ovalem Leib, keine Mitosen, keine Spindelformen. Glykogen ist ïberall reichlich, besonders in den mittleren Schichten. Vermehrung der Knorpelzellen innerhalb der Höhlen ist nicht zu konstatieren.

10. 7 Tage nach Implant.

a) Einhüllung in großes Netz; Alkoholfixation.

Der Befund deckt sich nahezu ganz mit dem gleichen vom 6. Tage. Leere Knorpelhöhlen nur in den äußersten Randpartien; sonst nur saftige Zellen bis zu 6 in einer Höhle. Die Abgrenzung gegen die Umgebung ist iberall scharf bis auf eine Stelle, wo man besonders bei Orceinfürbung: deutlich eine Durchmischung der Knorpelzellen mit den Fibroblasten des Netzes beobachten kann. Einzelne Kapseln am Rand sind hier leer, einzelne noch ganz deutlich gefüllt, die aus den Kapseln entbundenen, vom Druck befreiten Zellen strecken sich, vor allem was ihre Kerne betrifft. Der Plasmaleib bildet eine lange Spindel, die braunrot gefärbte Grundsubstanz rerschwindet ganz allmählich. Bei Pyroninfärbung sieht man Leukocyten in die eröffneten Höhlen eindringen.

b) Netzimplantation. Sublimatfixation.

2 Knorpelstïcke sind mit der Knochenseite einander zugekehrt, in

Deutsche Zeitschrift f. Chirargie. LXXV. Bd. 
großes Netz eingeschlossen. Beide Stücke enthalten viel nekrotische Knochensubstanz und viel verkalkten Knorpel. Die Absetzung des Knorpels gegen die Umgebung ist überall ganz scharf. In den oberflächlichen Schichten finden sich 2-3 Lagen abgeplatteter Spindelzellen, daun kommen im nicht verkalkten Knorpel nur ganz junge saftige Kapselzellen bis zu 12 in einer Knorpelhöhle mit ganz homogener Grundsubstanz. Im verkalkten Knorpel sieht man durch die stark mit Hämatoxylin gefärbten Kapseln die runden, stark konturierten Zellen. Besonders in den LitioncarminOrceinschnitten fällt die enorme Zellvermehruug auf; hier sieht man noch besser die Kerne des verkalkten Knorpels von genau dem gleichen Typus, dann noch einzelne kernlose Partien in den oberen Schichten, in den tieferen auch schon ruhende, abgeplattete, der Wand der Höhle dicht anliegende Spindelzellen ohne Kapsel. Glykogen ist nicht vorhanden.

11. 7 Tage nach Implant.

Alle 3 Knochenstückchen liegen zusammengebacken unter dem Dünndarm und der oberen Blinddarmkuppe der hinteren Parietalserosa auf und sind vollkommen frei beweglich. Alkoholfixation.

Die Knorpelstückchen sind von einer augenscheinlich rom Netz herrührenden Bindegewebskapsel allseitig eingescheidet. Es fand also eine sekundäre Lösung aus dem Zusammenhang mit dem Netz statt. Auch hier besteht eine ganz auffallende Vermehrung der Knorpelzellen, doch findet dieselbe nicht haufenweise innerhalb einer abgesehlossenen Knorpelhöhle statt, sondern es finden sich höchstens Complexe von 2 Zellen zusammengelagert; ixo allgemeinen liegt jede Zelle isoliert. Auch finden sich nicht einheitlich die jungen Zellformen im Knorpel, wie bisher, sondern nur sehr vereinzelt, teils in oberflächlichen, teils in basalen Schichten. Die Zellform ist gewöhnlich spindelig, olne die deutliche Kapsel, die Kerne klein, rund, ohne feines Chromatingerüst, mebr kompakt gefärbt, so wie sie sich im ruhenden Knorpel finden. In den basalen Schichten überwiegen öfters die sich erbolenden Formen, besonders im verkalkten Knorpel. Einwanderung von Zellen findet nirgends statt, auch keine Metaplasie in Bindegewebe. Die einzelnen Knorpelzellen enthalten in allen Schichten enorm viel Glykogen, viel mehr, als bisher jemals gesehen wurde.

Hier hat also nur eine temporäre Verwachsung stattgefunden, nach Lösung derselben aber kein Absterben sondern Überleben. Die Bläschenformen sind größtenteils sehon in ruhende Formen zurückgebildet, aber ohne daß eine regressive Metamorphose sich eingestellt hätte. Dafür sprechen auch die Vergleichspräparate von rubendem menschlichen Knorpel.

12. 10 Tage nach Implant.

3 Stückehen zusammen am Mesenterialansatz einer Dünndarmschlinge adhärent. Sublimatfixation.

Die 3 Stückchen sind von einem feinen Zellbelag eingescheidet, au einzelnen Stellen von einem fibrillären Gewebe, das sich septenförmig zwischen die einzelnen Stïckchen erstreekt. Die Abgrenzung gegen den Knorpel ist weder im zelligen noch in fibrillären Teil überall ganz scharf. Besonders da, wo in den oberflächlichen Knorpelschichten lebhafte Zellwucherung stattfindet, zeigen sich in beiden Komponenten so viel Kerne, $\mathrm{da} B$ eine scharfe Scheidung der Knorpelgrundsubstanz von dem Einseheidungsgewebe nicht zu machen ist. Alle Knorpelstüekchen sind in den ba- 
Silen Schichten stark verkalkt, und besonders hier finden sich diese eben erwähnten Zonen. An einem Pol des am stärksten kalkhaltigen Stückes kommt es so zn einer hochgradigen Durchmischung, indem einesteils von den Markräumen her junges Granulationsgewebe in den Knorpel eindringt, andererseits die Zellstränge des Einscheidnngsgewebes zwischen die Grundsubstanz des Knorpels einwachsen, wobei die Knorpelzellen unter Verlust der Kapsel darin aufgenommen werden. Direkt anliegend sind die Knorpelzellerı in ihren Höhlen stark gewuchert, jung, vollsaftig, auch im verkalkten Teil des Knorpels. Gerade hier fällt die starke Zellvermebrung auf neben einzelnen vorhandenen Karyolysen. In diesem Knorpelstück sind nur die oberflächlichsten Schichten zugrunde gegangen. Der basale Knorpel ist sehr resistent. Im andern Stiick sind es gerade die superfizielleu Schichten, die besonders am Rand eine enome Zellwucherung zeigen, so dal hier dichtgedrängt Kapselzelle an Kapselzelle liegt. Dieselben nehmen gegen die Oberfläche zu spindelförmige Gestalt an und gehen dann ganz entschieden in das Finscheidungsgewebe über. Man sieht in letzterem nicht nur platte Spindelzellen, sondern auch solche mit Kernbläschen. Gegen den anderen Pol des Stückchens werden dann in der gleichen Schicht die Zellen etwas spärlicher und die Begrenzung gegen die Oberfläche ganz scharf. In diesem Bereich sind besonders schöne Mitosen zu finden. In den tieferen Schichten zeigt sich hier entschiedene Säulenstellung. In dem nicht verkalkten dritten Knorpelstückehen aus der Fossa intercond. ant. besteht genau das gleiche Verhalten mit absolut scharfer Abgrenzung der Grundsubstanz gegen das Einscheidungsgewebe und reichlicher Wucherung der Knorpelzellen, die oft bis zu sechs in einer Kapsel, besonders in den basalen Schichten sich finden. Glykogen findet sich sehr reichlich im Knorpel in ganz unregelmäBiger Verteilung, auch in den rerkalkten Teilen des Knorpels, dagegen da nicht, oder nur sehr spärlich, wo keine scharfe Scheidung zwicchen Knorpel und einscheidendem Gewebe stattfindet.

13. 11 Tage nach Implant.

Alteres Tier.

a) Netzimplantation; Alkoholfixation. Der Knorpel rubt mit seiuer Basalseite dem Netz auf, ist an seiner Gelenkfläche mit einer feinen Zellschichte überkleidet, gegen die er nicht überall scharf abgesetzt ist. Man sieht an vielen Stellen teils einen dichten Wall von Granulationszellen, der eine Differenzierung des Knorpelrandes von demselben unmöglich wacht, teils direkte Loslösung einzelner Zellen aus dem Knorpelverband und Übergang in das einscheidende Gewebe. Die Knorpelzellen selbst sind in allen Schichten dicht gedrängt, basal wie superfiziell, lassen aber nicht die deutliche Kapsel erkennen wie im vorigen Fall, sondern liegen höchstens zu drei in einer Höhle und zeigen fast immer Spindelform. Die Kerne sind gewöhnlich bläschenförmig, an einzelnen Stellen der Oberfläche besteht ausgedehnte Karyolyse. Striebweise findet sich auch einmal völliger Kernschwund durch die ganze Dicke des Knorpels, aber nicht an der dünnsten Stelle. Die basal mitgetroffenen Kuochenbälkchen sind ganz kerulos; im Mark siebt man rom Netz her eingedrungene Fibroblastensprossen mit Gefäßen. Glykogen findet sich verschieden reichlich in allen spindelförmigen Knorpelzellen.

b) Sublimatfiration einer Netzimplantation zeigt genau das gleiche 
Verhalten. Nur ist hier die Abgrenzung der Grundsubstanz gegen das einscheidende Gewebe sehr deutlich.

14. 12 Tage nach Implant.

Älteres 'Tier'. 3 Knorpelstückchen liegen eng verbacken in der rechten Zwerchfellkuppe hinter der Leber der Parietalserosa an und sind nicht verklebt. Sublimatfixation.

Anch bier zeigen sich die Knorpelstückchen in eine Bindegewebskapsel eingehüllt, die sich aber von ihrem Mutterboden sequestriert hat. Trotzdem ist kein Absterben eingetreten, sondern der Knorpel verhält sich in den dünnen Randschichten genau so wie am 10. Tag. Es besteht sehr schöne Kapselbildung mit starker Vermehrung der Zellen in einer Hölle, so daß sie oft bis zu 6 an Zahl dichtgedrängt aneinander liegen. In den dickeren Knorpelschichten, besonders da, wo noch Knochen mitgetroffen, zeigt der Knorpel selbst ausgedehnte Schrumpfung der Zellkerne; die Knochenbälkchen sind völlig kernlos.

Auffällig ist jedenfalls, trotz der Lösung aus dem Verband, der enorme Zellreichtum des Knorpels und die vollkommene Intaktheit der Knorpelzellen gerade an den dünneren, zugespitzten Knorpelenden, wo jedenfalls der zellösende Einfluß der Peritoneallymphe am größten war. Der Gilykogengehalt ist wieder sehr reichlich.

15. 14 Tage nach Implant.

Älteres Tier.

a) Laparotomiewunde mit adhärentem Netz, in das ein Knorpelstiick eingeheilt. Der Knorpel ist zu 2 parallel liegenden Platten eingeknickt, zeigt an beiden Enden noch fibrilläres Gewebe. Zwischen beide Platten schiebt sich das stark bindegewebig veränderte Netz ein, das den Knorpel mit einer dichten fibrillären Scheide umgibt. Die Knorpelgrundsubstanz ist von der Hiulle überall scharf geschieden, ebenso der sehnige Teil; letzterer ist durchaus nicht kernlos, sondern läßt noch die Übergangszone von Bindegewebe und Knorpel deutlich erkennen. Man sieht besonders bei Lithioncarmin-Orcein deutlich den Übergang zu den Kapselzellen. Die Knorpelzellen selbst zeigen sich stark vermehrt, bis zu 8 tund melhr in einer Höhle, oft in Säulenstellung gelagert. Auch Mitosen sind zu seben, daneben wieder die Sichelzellen mit dem kleinen, kompakten Kern. Karyolysen und Pyknosen sind nicht vorhanden, nur vereinzelte, kleinste Inseln kernloser Grundsubstanz. In den äußersten Knorpelenden sieht man stellenweise das Einwachsen von Gefäßschlingen. Der in Verkalkung begriffene Basalknorpel ist auch noch dentlich kernhaltig. Bei van Gieson zeigt sich, daß in den einander zugekehrten, superfiziellen Schichten durch die exzessive Zellvermelrung die Grundsubstanz auf wenige feinste Streifen reduziert ist. Der Knorpel gewinnt so das Aussehen einer Bienenwabe. Dieser allmähliche Untergang der Grundsubstanz schwächt matiurlich die Stützfähigkeit.

b) Netzimplant.

Die Zellwucherung ist noch viel ex- und intensiver, so daß in vielen Schichten gar keine Grundsubstanz mehr vorhanden ist. Dabei ist auch die Säulenstellung verloren gegangen und die Zellform verändert; es finden sich viel mehr polygonale und Spindelformen. Besonders in diesen veränderten Teilen ist die Glykogenreaktion sehr deutlich, man findet solches 
auch frei in der Zwischensubstanz. Resorptionserscheinungen bestehen nicht; die Knorpelkapseln sind überall sehr deutlich.

16. 16 Tage nach Implant.

Zwei Knorpelstückchen im großen Netz eingehüllt. Einscheidung wie im vorigen Fall ohne aktives Vortreten von Gefäßschlingen.

Trotzdem besteht hier in einzelnen Teilen eine auffälig starke KaryoIyse. Andere Partien verhalten sich genau so wie im vorigen Stadium. Das Zwischengewebe zwischen den einzelnen Stückchen ist myxomatös verändert -- Vorstufe der späteren Markraumbildung. Der Glykogengehalt ist auf einige zentral gelegene Zellen beschränkt.

17. 19 Tage nach Implant.

Laparotomiewunde mit 3 adlärenten Knorpelstücken.

In den beiden zunïchst der Wunde gelegenen Stückchen starke Zellyermehrung. Mangel jeder regressiven Metamorphose. In dem andern Stück, das entfernt von der $W$ unde der Parietalserosa adhärent ist, zeigen sich die Knorpelzellen viel weniger aktiv und sind fast alle abgeplattet Der Kern ist kleiner, viel weniger bläschenförmig, die Kapsel auch bei Orceinfärbung nicht zu erkennen. Das Glykogen fehlt vollkommen.

18. 22 Tage nach Implant.

Adhärenz an der Laparotomiewunde. Der Zellgehalt des Knorpels ist etwas geringer als am 14. Tag; so daß die Grundsubstanz wieder etwas mehr hervortritt. Die Abyrenzung gegen die Einscheidung ist sehr deutlich.

19. 25 Tage nach Implant.

a) Adhärenz an der Laparotomiewunde. Das einscheidende Gewebe ist fibrillär, sehr zellreich; besonders gegen das Cavum peritonaei zu grenzt an die Knorpelgrundsubstanz ein dichter Zellwall. Die Knorpelzellen sind viel friseher als bei 22 Tagen wit sehr sehönen Kapseln, einzelnen Mitosen, bis zu 8 in einer Höhle an Zahl. An einem Rand finden sich einzelne schmale, kernlose Zonen; an einzelnen Stellen mit excessiver Zellvermehrung bestehen Karyolysen mit Platzen des Kerns und Freiwerden des Chromatins. Die Rarefizierung der Grundsubstanz ist besonders bei van Gies on gut zu sehen. Die Glykogenreaktion ist eminent deutlich. adhärent.

b) Knorpel durch ganz feine Spangen der vorderen Magenwand

Hier zeigt sich auf der einen Seite ein aktives Einwuchern des einscheidenden Zellwalls in den Knorpel mit Aufnahme ron Knorpelzellen in den Pannus. Auf der andern Seite ist eine tendinöse Insertion mit transplantiert -und sind die Fasern desselben homogen gequollen, kernlos; zwischen denselben sind Zellen eingewandert. Die Knorpelzellen selbst sind nicht so jugendlich wie bei a, sondern mit mehr kompahtem, kleinem Kern; auch die Kapsel ist nicht so ausgesprochen.

c) Knorpel der linteren Parietalserosa adhärent.

Sehr starke Karyolyse in den oberen Schichten. Pyknosen in den basalen Lagen. Hier einzelne Zellen mit auffallend groBem Glykogengehalt, mit Hm-Erythrosin als wieder erholte Kapselzellen nachweisbar. Die Bedingungen zum Fortleben sind hier entschieden ungünstiger.

20. 30 Tage nach Implant.

a) Netzimplantation.

Hier ist ein Knorpelknochenstiick überpflanzt. Der Knorpel selbst ist 
ganz erholt wie am 14. Tage. Der Knochenteil ist schalig von ihm abgehoben, durch ein sehr gefäßreiches Markgewebe mit großen Lymphocyten und kleinen Rundzellen. Die alten Knochenbälkchen selbst sind nicht mehr vorhanden, sondern augenscheinlich dureh ein ganz junges Knochengewebe mit großen Knochenkörperchen und deutlichen Osteoblastenreihen ersetzt. Diese Reihen finden sich nur anf der dem neuen Mark abgewendeten Seite der Knochenbalken. Der Knorpel selbst ist nicht mehr so ganz kernreich wie am 14. Tage. Glykogen findet sich besonders in den basalen Teilen.

b) Das andere Stück ist kernärmer; in einzelnen, schmalen Zungen sogar ganz kernlos. Die basalen Zellen zeigen bei gut erhaltener Kapsel plumpe Granulierung des Kerns. Glykogen ist nicht vorhanden.

2 i. 32 Tage nach Implant.

a) Adhärenz an Laparotomiewunde. Enormer Zellreichtum der beiden Knorpelstückchen. Nur jugendliche, schöne Kapselformen. Einscheidung sehr deutlich gegen Knorpel abgesetzt. Viel Sichelformen im Knorpel; Glykogen nicht sehr reichlich.

b) Netzimplantation.

Im wesentlichen derselbe Befund. Vom freien Rand her Aufzehrung der Grundsubstanz durch einen dichten Zellwall.

22. 35 Tage nach Implant.

3 Knorpelstückchen in einer Reihe im grolien Netz.

Im Knorpel sind nur die basalen Teile karyolytisch verändert. Der Zellgehalt ist nicht so reichlich wie bei Adhärenz an der Bauchwunde, daher auch die Rarefizierung der Grundsubstanz weniger ausgesprochen. Der Glykogengehalt ist mittel; die Kapsel überall deutlich. Hier zeigt sich zum erstenmal an der basalen Seite des Knorpels eine Apposition von Knochenbälkchen an den Knorpel. Die in die alten Markräume eingewucherten Fibroblasten des Netzes ordnen sich in Osteoblastenreihen und bilden Knochen. Eine Mitverwendung von Knorpelzellen findet dabei nicht statt, im Gegenteil ist der Knorpel in diesen Bezirken oft ganz kernlos.

23. 40 Tage nach Implant.

a. Adhärenz an Laporatomiewunde.

Der Knorpel ist in eine derb fibrilläre Bindegewebskaspel eingebettet, gegen die Grundsubstanz scharf abgesetzt. Auch hier entsteht ein schaliges Gebilde dadurch, daß sich an der basalen Knorpelfläche ein neues Markgewebe entwickelt hat, das an der dem Knorpel abgewendeten Seite einen Belag ron Knochenkälkchen zeigt. Die Knochenbalken enthalten große, junge Knochenzellen, an der Markseite liegen ihnen reihenförmig Osteoblasten an. Auch an den basalen Knorpelteilen finden sich zarte, neugebildete Knochenspangen, die besonders bei Orceinfärbung gut kenntlich sind. Vom Markgewebe erstrecken sich auch Bindegewebs-Gefäßknospen in den Knorpel hinein. Die Knorpelzellen werden hier unter Verlust der lichtbrechenden Kapsel in den Zellwall mit einbezogen. Das Knorpelknochenstäck erscheint gegen die Excisionsfläche betrachtet in allen Durchmessern entschieden etwas vergrößert. Gegenüber dem 30 . I'ag ist der Zellgehalt im Knorpel auch entschieden vermehrt. Die Abgrenzung der Oberfläche gegen das Einscheidungsgewebe ist im allgemeinen sehr scharf, die blasigen Knorpelzellen liegen den Kernspindeln des Bindegewebes 
unvermittelt gegenüber, nur an einzelnen Stellen finden sich in den oberen Knorpelschichten auch längsgestreckte, mehr platte Zellen, deren Kern aber immer noch ein granuliertes Innere zeigt. Sonst sind die Knorpelzellen in allen Schichten gleich, von dem schon oft beschriebenen Charakter, bis zn 8 an Zahl in einer Höhle. Nekrotische, kernlose Bezirke finden sich nirgends. An den seitlichen Schnitträndern findet ein direkter, allmählicher Übergang der Knorpelzellen in das einscheidende Gewebe statt. Die Grundsubstanz des Knorpels ist überall gleichmäßig homogen, in den superfiziellen Schichten ungefärbt, in den tieferen stark durch $\mathrm{Hm}$ tingiert. Gerade hier ist der Glykogengehalt noch sehr beträchtlich, oft ist der ganze Zellleib durch feine, hochrote, glänzende Görner ausgefüllt. Mitosen sind nirgends zu sehen, dagegen häufig die schon viel erwähnten Sichelformen.

b) Netzimplanation.

Auch hier besteht eine entschiedene Größenzunahme in Höhe und ror allem in Breite. Doch ist hier der Höhepunkt der Entwicklung schon überschritten, das Einscheidungsgewebe sehr gefäßarm. Auch der Zellreichtum des Knorpels ist geringer, die großen Bläschen treten stark zurïck gegen teils abgeplattete, kompaktgefärbte Kerne, teils solche mit zackigen Konturen, hellerer Körnung und geschrumpftem Plasmaleib. Auch hier finden sich die jugendlichsten Formen wieder in den zugespitzten Seitenrïndern. Glykogen ist nicht rorhanden. Knochenapposition an der Knorpelbasis ist auch hier deutlich zu sehen.

24. 4 i 'Tage nach Implant.

a) Adhärenz an der Laparotomiewunde.

Hier ist in gleicher Weise wieder ein schaliges Gebilde entstanden mit einem zentralen Markgewebe, das viele GefäBsprossen in den Knorpel lineinschickt mit Apposition ron Knochenbälkchen an denselben. Hier in den basalen Schichten sind die Kerne der Knorpelzellen zackig verändert, zum großen Teil geschrumpft. In den superfiziellen Schichten finden sich nur ganz junge Knorpelzellen, die sich besonders an den Seitenrändern wallartig anhäufen. Nur hier findet sich Glykogen als schmaler Saum in den Zellen.

b) Adhärenz an der hinteren Parietalserosa.

Der Knorpel enthält nur ganz junge Knorpelzellen mit reichlichem Glykogengehalt. Die im übrigen gegen den Knorpel scharf abgesetzte bindegewebige Kapsel entsendet vielfach verästelte Gefäßsprossen in den Knorpel mit schmaler, durch Orceinfärbung sehr deutlicher Verknöcherungszone. Die Knorpelzellen werden beim Einbruch der Sprossen in die Knorpelhöhlen mit aufgenommen.

Es besteht hier ein anffallender Unterschied in der Vitalität gegenüber dem 25. Tg. (19c) wo bei gleicher Lokalisation der Knorpel fast ganz abgestorben war.

25. 50 Tage nach Implant.

3 Knorpelstückchen eng miteinander verbacken, in großes Netz eingehüllt. Dasselbe zeigt sehr ausgedehnte Gefäßentwicklung und bildet ïber der elemaligen Gelenkfläche eine feine, fibrilläre Scheide. An der Basis findet sich ein gut entwickeltes Markgewebe mit einer dünnen Knochenschale gegen das Netz, die beiderseits eine Osteoblastenschicht zeigt. Anch 
an den Knorpel findet basal Knochenapposition statt. Die Abgrenzung der Oberfläche gegen das einscheidende Gewebe erscheint fast immer scharf. nur an einzelnen Stellen findet sich eine solche Zellanhäufung, daß ein sicheres Urteil nicht möglich ist. Der Knorpel selbst verhält sich im allgemeinen wie der ruhende Knorpel; in den Basalteilen sind die Kapseln stark durch Hm gefärbt, der Zellkörper größtenteils geschrnmpft, der Kern klumpig, kompakt gefärbt. Nach oben zu platten sich die Knorpelzellen $a b$, werden polygonal tnd spindelig und zeigen hier größtenteils noch bläschenförmigen Kern. Keralose Bezirke sind sehr selten. Glykogen ist besonders in den oberflächlichen Schichten sebr reichlich.

26. 62 Tage nach Implant.

Netzimplautation. Der schon in vorigen Stadium erwähnte Unterschiet zwischen den oberflächlichen und basalen Schichten ist hier noch deutlicher ausgesprochen; in ersteren nur jugendliche Zellformen, in letzteren Karyolyse und Schrumpfung, teilweise aber auch Bezirke mit sehr gut erbaltenen Knorpelzellen. Die Knochenapposition an die Knorpelbasis nimmt $z u$, wobei die neugebildeten Spangen rom verkalkten Knorpel ganz scharf abgegrenzt sind.

2.7. 70 Tage nach Implant.

a) Adhärenz an Parietalserosa.

2 Knorpelstücke liegen direkt übereinander. Das gegen die Bauchhöhle gekehrte, der Wunde nicht direkt anliegende zeigt eine viel größere Durchwachsung von Bindegewebegefäßsprossen, als das unter besseren Ernährungsbedingungen stehende andere. Sonst besteht genau das gleiche Verhalten wie in den letzten Stadien: jugendliche Formen in den oberen Schichten, in den basalen Schichten Pyknose und ron hier aus nach oben fortschreitende Umbildung des Knorpels in Knochen, wieder mit direkter Metaplasie der Knorpeizellen.

b) bei der Netzimplantation ist der ganze Knorpel von blasigen Zellformen angefüllt mit sehr deutlicher Kapsel, ohne daß schon eine Um. bildung in Knochen sich angebahnt hätte.

28. $\$ 1$ Tage nach Implant. im Netz.

Der in der Mitte gelegene Markraum (siehe frühere Stadien) ist dureh appositionelles Wachstum der Knochenbälkchen stark in seinem Umfang reduziert, auch in den basalen Knorpelschichten hat die Verknöcherungszone an Breite und Höhe zugenommen. Die Knorpelzellen zeigen direlrte Metaplasie zu Knochenzellen, im übrigen haben sie überall deutliche Kapsel, schaif begrenzten bläschenförmigen Keru, lassen jedoch keine Vermehrung mehr erkennen. An einzelnen Stellen in verschiedener Tiefe sieht man Karyolysen; die Grundsubstanz ist überall gleichmäßig homogen. Fon der ehemaligen Gelenkfläche her dringen stellen weise Fibroblasten in Zapfenform ein, besonders in der Nähe kleinster Gefäße. Die Knorpelgrundsubstanz wird dabei vollkommen aufgelöst, die Kapselzellen unter Erhaltung der Kapsel in den Fibroblastenwall miteingezogen. Sonst ist die Einscheidung des Knorpels eine absolut scharfe, mit einer verschieden dicken Schicht von enggeschachtelten Spindelzellen. Durch die Bindegewebsgefäßzapfen werden kleinste Knorpelstückchen direkt sequestriert, sodaß schließlich nur Inseln ron Kapselzellen bleiben. Glykogen ist nur in den der Verknöcherungszone zunächst gẹlegenen, basalen Schichten nachweisbar, 
als feinste, spärliche Körnchen auftretend. Die darauf folgende Schicht zeigt exquisite Säulenstellung.

Wenn ich nun in Kürze den Befund noch einmal zusammenfasse, so gestaltet sich der Verlauf der Reaktion folgendermaßen: Zunächst findet ein mehr oder weniger intensives Zugrundegehen von Knorpelzellen statt, das sich aber nicht auf einzelne Schichten des Knorpels (oberflächlicher, Säulen-, großblasiger Knorpel) beschränkt, sondern mehr regellos auftritt und auch oft nur herd-oder inselförmig zu finden ist. Am meisten zeigt sich diese Degeneration in den dickeren Knorpelteilen im Centrum, die der Ernährung durch den Saftstrom im Bauchfell weniger zugänglich sind. Eine auslaugende Wirkung desselben auf die zugespitzten Knorpelränder ist nicht zu beobachten, im Gegenteil, dieselben zeigen sich viel besser ernäbrt als im Centrum. Das implantierte Stück wird rasch von einem Leuk.-Wall umgeben, dieselben ordnen sich schon nach 16 h pallisadenförmig zu einem Wall, der die Grundsubstanz direkt aufzehrt. Dies Verhältnis ist auch nach 32 Tagen noch zu beobachten. Die regressiven Veränderungen der Knorpelzellen besteben zum Teil in ausgesprochener Karyolyse, zum Teil in Pyknose und Kernzertrümmerung. Progressive Veränderungen zeigen sich schon nach $16 \mathrm{~h}$, man sieht dann schon die sich wieder erholenden Kapselformen mit rundem bläschenförmigem Kern, dem zart granulierten Plasmaleib und der stark lichtbrechenden Kapsel, Formen, die durch den ganzen Versuch hindurch zu beobachten sind und größtenteils sehr restisent sind. Öfters beobachtet man auch eine Rareficierung des Kerngerüsts in ihnen, ein Platzen des Kerns und ein Freiwerden des Chromatins. Diese Zellen können sich in einzelnen Knorpelhöhlen excessiv vermehren unter reichlicher indirekter Kernteilung. Solche Mitosen sind bis zum 40. Tag und weiter zu sehen - Sehiefferdecker fand Mitosen im Knorpel immer nur während des fötalen Jebens. Ist die Vermehrung in einer Knorpelhöhle sehr stark, so bilden sich einzelne junge Formen wieder in alte rubende um, die dann als an den Rand der Höhle gedrängte Sichelformen auftreten, wie sie auch schon Enderlen beobachtet hat. Ich möchte sie nicht wie Enderlen als zugrunde gehende, sondern als ruhende Zellformen ansprechen, da sie auch noch an 32. und 40. Tag zu sehen sind. Die Anfangstadien der progressiven Veränderungen sind am besten bei der Färbung mit polychromem Metbylenblau zu beobachten; die sich erholenden Zellen zeigen einen ganz schwach blau gefärbten Kern mit zartrosa Plasmaleib, die noch stehen gebliebenen oder in Rückbildung begriffenen einen tiefblauen Kern mit violettem Plasmaleib. Sind bei der Übertragung des Knorpels Teile eines Lig. cruciatum oder des Kapselansatzes mittransplantiert 
worden, so verhalten sich diese viel weniger resistent, ihre Kerne sterben rasch $a b$ und sie werden von Wanderzellen infiltriert. Nach $48 \mathrm{~b}$ ist dann bis zum 40. Tag eine neue, noch gewöhnlich geringe streifige Umwandinng der Grundsubstanz in den obersten abgeplatteten Lagen des Knorpels, der ehemaligen Gelenkoberfläche entsprechend zu beobachten, die aber, wie gesagt, imner nur eine beschränkte bleibt und deren Deutung oft wegen der dichten Anhäufung von Zellen eine zweifelhafte bleiben muß. Barth fand eine solche umschriebene Metaplasie in den obersten bindegewebigen Schichten des Knorpels auch bei menschlichen Gelenkkörpern. Die einzelnen Knorpelschichten sind in ihrer Resistenz sehr verschieden, manchmal, besonders in den Anfangstadien ist der großzellige, basale verkalkte Knorpel auffällig widerstandsfäbig, später zeigt er sich besonders in den mittleren Stadien (35.-60. Tag) sehr kernarm bis kernlos. Die Resistenzfähigkeit der einzelnen Knorpelzellen scheint aber eine individuell bedingte $\mathrm{zu}$ sein und von äußeren Vlomenten, von den Ernährungsbedingungen abzubängen. Keinesfalls ist ein ausnahmeloses Zugrundegehen des großzelligen Knorpels $z u$ beobachten, wie es Schmitt ausspricht, im Gegenteil, der ganze Knorpel bildet sich in großzelligen Knorpel um.

Fand bei Implantation im Netz eine sekundäre Lösung aus demselben statt, handelte es sich also nur um eine temporäre Verwachsung, so bilden sich die jugendlichen Zellformen wieder in alte ruhende um; auch sind, wenn es sich um ältere Tiere handelt, die Jugendformen manchmal nicht so ausgesprochen wie bei ganz jungen Tieren. Doch gilt dies nicht für alle Fälle. 14 Tage nach der Implantation sieht man zum erstenmal Gefäßschlingen gegen den Knorpel gerichtet entstehen, die am 40. und 45. Tag stark zunehmen, in den Knorpel teils von der Gelenk-, teils von der basalen Seite her eindringen, die aus den Knorpelhöhlen frei werdenden Zellen in das sie begleitende Bindegewebe mitaufnehmen, aus letzteren, resp. den Fibroblasten einen Osteoblastenbesatz bilden, der dann, gegen den Knorpel gerichtet, einen feinen Knocheusaum ausscheidet. Dieser Knochenbesatz nimmt schließlich immer mehr zu. Der sehr häufig weitüberpflanzte Knochenteil an der Knorpelbasis stirbt immer schon in den ersten Tagen ab, zeigt sich schon nach $16 \mathrm{~h}$ kernlos, das Markgewebe ist stark von Blutungen durchsetzt, zeigt nur geschrumpfte Kerne, Leukocyten fehlen fast ganz. Nach 24 h dringen in die Markräume junge Fibroblasten ein, auch Leuko- und Lymphocyten, die ersten lassen sich zurückverfolgen bis zum Einscheidungsgewebe. Nach 10 Tagen erkennt man, wie diese jungen Bindegewebszellen sich in Reihen legen, den Trümmern der mehr oder weniger erhaltenen Knochengrundsubstanz sich anlegen und 
also als Osteoblasten fungieren unter Benützung der alten Knochengrundsubstanz und Bildung von neue. Reste dieser alten Grundsubstanz mit dem reihenförmigen Belag von neuen Knochenbildnern siebt man noch am 16. Tag. Als Vorstufe der später zu beobacbtenden Bildung neuer Markräume erkennt man hier eine myxomatröse Umbildung des Zwischengewebes, das am 30. Tag damn durch typisches neugebildetes Knochenmark ersetzt ist und vor allem durch den Gehalt an großen Lymphocyten kenntlich ist. Gegen die Knochenbälbchen und gegen die Knorpelunterfläche zeigt dieses Mark immer einen dichten Wall von Osteoblasten. Es bildet auch auf seiner den Knorpel abgewendeten Seite Knochen, sodaß ein schaliges Gebilde mit einem centralen Markraum und einer teils knorpeligen, teils knöchernen Schale resultiert - besonders schön zu sehen vom 50. Tag ab. - Die Knochenneubildung nimmt dann unter Reduktion des Markraumes zu, und es findet von der Basis des Knorpels aus ein allmählicher Ersatz desselben durch appositionell gebildeten Knochen statt; wobei auch die Knorpelzellen selbst unter direkter Umwandlung in Osteoblasten sich beteiligen. Diese direkte Metaplasie tritt aber gegen die Apposition sehr stark zurück. So wird schließlich von der Basis her durch Umwandlung und von der ehemaligen Gelenkfläche her durch Einwachsen von Gefälischlingen und Bildung einer Knochenscbale an denselben der Knorpel durch Knochen ersetzt. Am 80. Tag ist dieses Endstadium allerdings noch nicht erreicht.

Eine wesentliche Größenzunahme des Knorpels nach der Übertragung findet nicht statt. Nur am 40. Tag erscheint das überpflanzte Stiick gegen den Defekt betrachtet etwas größer. Eine Volumensvermehrung durch Expansion oder Quellung, wie sie Enderlen fand, konnte ich niemals beobachten.

Eine grundlegende, gesetzmäßige Differenz zwischen dem Verhaltea des Knorpels an den verschiedenen Implantationstellen (Netz, Laparotomiewunde, binteres Bauchfell, Darm) besteht nicht, es finden sich oft direkt widersprechende Befunde, nur scheint die Reaktion bei Implantation an der Bauchwunde rascher abzulaufen, als bei Einwachsen im Netz, wo die jugendlichen Kapselformen qualitativ und quantitativ länger zu beobachten sind. Geringer Blutgehalt des sekundären Mutterbodens bedingt in allgemeinen geringere Aktivität oder raschere Riickbildnng der Reaktion.

Die im rubenden Knorpel vorhandene Differenz der Zellform nach Schichten versehwindet bei Überpflanzung im allgemeinen rasch, besonders die oberflächlichen abgeplatteten Spindelzellen wandeln sich baldigst in jugendliche Formen um bis auf die schon erwähnte un- 
schriebene Metaplasie. Ob diese Formveränderung durch die andersartigen Druckverbältnisse bedingt ist, wie $\mathrm{Zahn}$ und Leopold meinen, durch die Ausschaltung des im Gelenk obwaltenden Innendrucks, wage ich nicht zu entscheiden. Nach den Ergebnissen von Braune und Fischer (cit. nach Enderlen), die den Knorpel als eine biegsame. elastische Masse darstellen, deren Form vom Innendruck, von der Muskelaktion u. s. w. abbängig ist, erscheint dies wahrscheinlich.

Meine Befunde baben mich also zu einer wesentlich anderen Ansicht geführt über die Lebensfähigkeit und Widerstandsfähigkeit des Knorpelgrewebes. Le opold, $\mathrm{Zahn}$ und $\mathrm{F}$ is che r erklären auf Grund ihrer Versuche, daß vom Mutterboden ïbertragener postfötaler Knorpel ausnahmlos einer raschen Resorption verfällt, oder wenigstens wie Fischer meint, eine rasche Metaplasie in jugendliches Fibroblastengewebe durchmacht. Die Beweiskraft dieser Versuche mag ja eine nicht sehr zwingende sein, da dieselben weit zurückliegen. aber auch in neuester Zeit Laben sich Barth und Lubarsch in ähnlichem Sinn ausgesprochen. Barth faßt das Endschicksal der künstlich erzeugten Gelenkkörper dahin zusammen, dal die sicher vorhandenen produktiven Vorgänge nur vorübergehende Erscheinungen sind und daß schließlich der ganze Körper der Resorption auf dem Wege des bekannten organischen Resorptionsprozesses verfällt, der am Knorpel von der 6 . Woche ab nacbweisbar ist. Von Erscheinungen, die an eine Resorption erinnern, beobachtete ich nur das Auftreten und Eindringen von Gefäßschlingen von Mark und Bindegewebe aus, diese zehren aber die Grundsubstanz nicht einfach auf, sondern sind im Gegenteil die $Z$ wischenträger zur Ausbildung eines neuen Gewebes durch Apposition von Knochen an den Knorpel. Es bandelt sich nicht um osteoides Gewebe, sondern um wirklichen Knochen. Ich konnte immer bei den Sektionen die Beobachtung machen, daß in den späteren Stadien die Knorpelstückchen viel härter, knochenähnlicher werden, so daß sie vom 30 . Tag ah, wenn auch nur kurz, entkalkt werdea muBten.

Gegen eine einfache Resorption von seiten des einscheidencien Gewebes spricht auch das absolute Fehlen von Riesenzellen in meinen Befunden. Barth spricht noch nach 6 Wochen von einem massenhaften Vorhandensein von Riesenzellen; mir ist bei der Durchmusterung meiner Schnitte kaum eine begegnet. Auch darin stimme icb mit Barth nicht überein, daß keine Umwandiung der Knorpelzellen in jugendliche Kapselform eintritt. Ich gehe allerdings nicht so weit, wie A. Schmitt, der dem Knorpel, besonders dem von ibm so ge- 
nannten äußern ungreordneten Knorpel eine ausgesprochene produktive Tätigkeit zuschreibt, während er den inneren, großblasigen Knorpel wie den Knochen ausnahmslos zu Grunde gehen läßt, teile aber auch absolut nicht Lubarschs Ansicht, der sagt: Knorpel ohne Perichondrium wird überhaupt kaum organisiert. Auch darin befinde ich mich mit Barth in Widerspruch, wenn er behauptet, daß die uiberpflanzten Knorpelstückchen als Zeichen regressiver Metamorphose häufig verkalken. Er fand das Auftreten dieser Verkalkung abhängig von der Art des Zusammenhanges des freien Körpers mit dem sekundären Mutterboden (Gelenkkapsel). Sie feblt nach inm bei loreiter Verwachsung; ist mehr oder weniger reichlich bei zartem Stil und am rejchlichsten bei sekundär frei gewordenen Körpern. Gerade letztere, deren ich auch mehrere beobachten konnte, zeigten sich aber bei mir niemals verkalkt, waren im Gegenteil inmer schon bei der Sektion viel weicher als die breit adhaerenten, besonders als die an der Laparotomiewunde festgewachsenen.

Mein Schlußwort geht also dahin, daß der aus der Kontinuitat in die Bauchhöhle versetzte Gelenkknorpel des Kaninchens eine sehr ausgesprochene Vitalität besitzt im Gegensatz $\mathrm{zu}$ den bis jetzt festgestellten Befunden und mit der Zeit eine Umwandlung in Knochengewebe durch Apposition und Metaplasie ohne gleichzeitige regressive Verändernngen erfährt, deren Endpunkt ich allerdings beim Abschlub meiner Versuche am 80. Tage noch nicht erreicht hatte. Diese ausgesprochene Vitalität fand ja Bartb auch bei den von ibm untersuchten menschlichen Gelenkkörpern, wo sogar nach 5 Jahren noch ausgesprochene Wucherung der Knorpelzellen festzustellen war.

Ob sich der perichondrale Knorpel ebenso verhält, müssen weitere Versuche lebren. Ein ähnlicher Befund würde dann den Ausblick anf eine praktische Verwertung in der plastischen Chirurgie eröffnen, eine Verwertung, die ja von König und Mangoldt schon vorweggenommen ist. Eine Umwandlung in Knochen wirde die Stützfäbigkeit eines frei überpflanzten Stückes Rippenknorpel usw. bedeutend erhöhen. Mangoldts eigene Versuche sprechen gegen eine derartige Umwandlung, nach ihm bleibt, wie schon erwähnt, der Knorpel nur im Bereich des Perichondriums am Leben. Auch eine Vereinfachung der Technik war bei der Bewahrheitung meiner bisher nur für den Gelenkknorpel gültigen Befunde zu erhoffen, da ja damit die Möglichkeit dẹs Überlebens auch bei freier Überpflanzung ohne temporären Zusammenhang mit dem Mutterboden möglich wäre. 
Im Anhang möchte ich nur nocb kurz über Versuche berichten, die ich mit Gelenkknorpel des Kaninchens anstellte, um ein Ü̈berleben unter einfachsten Bedingungen zu konstatieren mit möglichstem Ausschluß jeder Zelleinwanderung und überhaupt jeden Kontaktes mit einem anderen Gewebe, unter ausschließlicher Ernährung des überlebenden Stïckchens durch den im Bauchfellraum zirkulierenden Saftstrom. Ich verdanke die Anregung dazu, wie so manche andere, Herrn Professor Aschoff.

Zu dem gedachten Zwecke wählte ich nun die Einheilung von in Kollodiumsäckchen verbrachtem Knorpel in die Bauchhöhle, eine Versuchsanordnung, wie sie besonders zu bakteriologischen $\mathrm{Z}_{\text {wecken }}$ besonders von französischer Seite scbon mehrfach verwendet wurde. Die Technik war folgende: Über einen möglichst gleichmäßig dicken Glasstab wurde durch wiederboltes Eintauchen in eine dicke Celloidinlösung und Trocknung ein an einem Ende offenes Säckchen gebildet, das nach dem Trocknen in ein Reagenzglas mit Kochsalzlösung verbracht und in Dampf sterilisiert wurde. Nach Einbringung der Knorpelstiickchen in diese Säckchen wurde dann das freie Ended urch eine Glasprothese abgeschlossen, das Säckchen darüber zugebunden und ein luftdichter Abschluß durch Überpinseln mit Celloidin zu erzielen gesucht. Darnach wurden die Kapseln in die Bauchhöhle verbracht, wo sie fast ausnahmslos reaktionslos einheilten und von den Tieren gut vertragen wurden. Die Versuche dehnte ich auf 7 Tage aus und lasse die Protokolle nun folgen.

1. Ca. 12. Stunden nach Implantation.

Prothese liegt im oberen Teil der Bauchhöhle zwischen Darmschlingen und Magen vollkommen unversehrt. Im Inuern finden sich 3 Knorpelstückchen und klare Flüssigkeit, die beim Kochen eine mäßige Trübung: zeigt. Mikroskopisches Bild:

Der ganze Knorpel ist sehr zellheich: in den oberflächlichen Schichten sind dieselben platt und ganz kompakt gefärbt, in den anderen Schichten großblasig, oft in Reihen stehend. Die Kerne sind teils deutlich begrenzte Bläschen mit feinem Chromatingerüst und mebreren ganz feinen Kernkörperchen; an einzelnen ist die Kernmembrau unregelmäßig zackig; ein anderer Teil der Kerne ist verklumpt, kompakt gefärbt an einen schlecht konservierten Monaster erinnernd. Einzelne Kerne zeigen wieder auffallende Chromatinarmut und Blähung. Der Zelleib und die Kapselkontur ist überall deutlich, ersterer bei den Pyknosen viel dunkler gefärbt. Die Grundsubstanz ist gleichmäßig homogen, leicht blaßblau, am Rand überall scharf konturiert.

2. 24 Stunden nach Implantation.

Die Spitze des Röhrchens ist mit klarer Lrmphe und einem feinen Gerinnsel gefïllt. Der Knorpel zeigt ausgedehnte Verklumpung aller Kerne. Bläschenförmige Kerne sind äußerst selten, nur in den Randschichten nach- 
weishar. Der Zellkörper ist diffus mit Hm gefärbt, klein, ohne Vakuolen. Die Grundsubstanz ist gleichmäßig homogen, nur in einem Stiickchen zeigen sich feine, lichtbrechende Spalten in derselben. Glykogenreaktion ist wie im rorigen Stadium negativ.

3. 36 Stunden nach Implantation.

Die Prothese ist in großes Netz eingeschlossen und, wie die ausgedehnte Zelleinwanderung zeigt, nicht unversehrt geblieben. Der Knorpel selbst ist von kompakt gefärbten Mykrokokkenhaufen umgeben und zum größten Teil kernlos, nur in den mittleren Schichten sieht man vereinzelte, sich erholende Kapselzellen.

4. $4 \mathrm{~s}$ Stunden nach Implantation.

a) Alkoholfixation.

Hier hat keine Zelleinwanderung stattgefunden. Die oberfläehlichen Zellen sind besser erhalten als die basalen, in letzteren sind die Knorpelhöllen teilweise mit unregelmäßigen Cheromatinklumpen gefüllt, teilweise läßt sich Kern- und Zellform noch erkennen, aber ohne Differenzierung: dureh die Doppelfärbung. An den mittleren Schichten finden sich mehr oder weniger häufig richtige Kernblasen, besonders im Centrum. Doch sind auch hier einzelne Chromatolysen und Unregelmäßigkeiten der Kernmembranen zu erkennen. Jedoch sehen die Zellen entschieden besser als nach 12 Stunden aus.

b. Sublimatfixation.

Hier sind die großen Kernblasen zwischen den geschrumpften Kernen noch viel dentlicher zu erkennen und überwiegen letztere oft.

5. 3 Tage nach Implantation.

Die Prothese ist von einer dicken Fibrinscheide umgeben; die trübe Flüssigkeit im Innern enthält Eiterkörperchen und Abkömmlinge fixer Gewebszellen.

Die Kerne sind großenteils ganz kompakt gefärbt, etwas geschrumpft, mit unregelmäßigem Rand. Hier zum erstenmal auch leere Knorpelhöhlen. In einem Stück finden sich in Gegensatz dazu wieder auffallend häufig Kernblasen. Dieses Stück enthält im Unterschied zu den anderen auch Kaochenteile.

Bei Orceinfärbung erkennt man, daß an den kleinen, ganz ruhenden Zellen feine Verästelungen zur Knorpelkapsel sich erstrecken, während bei den anderen Formen die ganze Kapsel straff ausgefüllt ist. Diese ruhenden Formen sind identisch mit den Spindelzellen der oberflächlichen Schichten. Eine Einwanderung von Zellen in den Knorpel oder eine Anlagerung an denselben ist trotz Konstatieruug derselben im Protheseninnern nicht vorhanden.

Bei einem anderen Versuch von gleicher Dauer, wo Infektion eintrat, finden sich fast nur leere Knorpelhöhlen.

6. 4 Tage nach Implant.

Prothese ist in stark verdicktes und hyperaemisches Netz eingerollt; eine Läsion am Säckchen nicht nachweisbar. 'Trotzdem finden sich Leuk. auch im Inneren der Hülse. Am Knorpel findet sich mit-iubertragen ganz kernloses Kapselgowebe mit sehr gut erhaltenen Fibrillen. Am Knorpel sind in den oberflächlichen Schichten noch Spindelzellen mit kompakten, aber gut conturierten Kernen, in den mittleren Schichten besteht ausge- 
dehnte Pyknose, in den tiefen Schichten ist der rötliche Zellleib noch dentlich, aber kein Kern mehr vorhanden. Im Centrum des Stückes findet sich verkalkter Knorpel; hier sind die Zellen in allen Schichten viel besser erhalten. Oberflächlich deutliche Spindeln, in den mittleren Schichten den ganzen Kapselraum ausfüllende Zellen, jedoch mit etwas zackiger Kernmembran; in der Tiefe ruhende Zellen mit Verästelung im Kapselraum und einem durchaus wohlgebildeten Kern. Dem Knorpel sind hier Leuk.und Wanderzellen aufgelagert, jedoch nirgends eingedrungen. Unmittelbar nach diesem ganz schmalen Streifen kommt wieder kernloser Knorpel. Die Bindegewebszellen in den mitübertragenen Knochenteilen sind tot.

7. 5 Tage nach Implant.

Wegen starker Infektion vollkommene Karyolyse.

8. 6 Tage nach Implant.

Prothese in großes Netz eingerollt und zum großen Teil mit klarer Flüssigkeit gefüllt, in der die Knorpelstuckchen schwimmen. Abimpfung auf Agar bleibt steril.

Alkoholfixation zeigt den Knorpel noch vollkommen kernlaltig. Die Zellen sind fast alle ruhend, in den tieferen Teilen multipolar mit Verästelung im Kapselraum, so wie bei 5 geschildert. Großblasige Zellen finden sich fast nicht. Wenn vorhanden, so zeigen sie zackig-stachelige Kernmembran, was besonders mit Orcein gut zu erkennen, also schon beginnende Kernschrumpfung. Sublimatfixation gibt das gleiche Bild.

9. 7 Tage nach Implant.

Alkoholfixation.

Trotz ausgedehnter Bakterienvegetation (Staph. pyogen. aur.) überall Kernfärbung. Die mittleren und tieferen Schichten sind ausgedehnt pyknotisch und karyolytisch, in den oberflächlichen Schichten finden sich deutlich bläschenförmige, wenn auch abgeplattete Kerne; diese lassen mit Orcein einen sehr schönen Plasmaleib erkennen, zeigen sich also resistenter. Das gleiche ergibt sich bei Sublimatfixation.

Nach $12 \mathrm{~b}$ ergibt sich also keine wesentliche Differenz gegenüber der freien Implantation, nach $24 \mathrm{~h}$ zeigt sich rasch zunehmende Pyknose ohne Zelleinwanderung, nach $36 \mathrm{~h}$ beginnen einzelne Bezirke im Knorpel sich wieder zu erbolen, es findet sich also eine Verspätung gegenüber der ersten Versuchsreihe nm ca. $24 \mathrm{~h}$. Diese Erholung tritt auch trotz scbwerer Infektion auf. Das Wiederaufleben nimmt nach $48 \mathrm{~h}$ noch zu, zeigt sich am ausgedehntesten am 3. Tag nach der Implantation, aber immer nur auf einzelne Bezirke beschränkt, nicht auf den ganzen Querschnitt verteilt, hält sich am 4. Tag noch aut gleicher Höhe, am 6. Tag ist aber trotz vollkommen aseptischen Verbaltens des Prothesen-Innern und fehlender Einwandrung schon beginnende Pyknose festzustellen, Veränderung der bisher scharf konturierten Kernmembran, Chromatinniederschläge auf derselben. Sehwere Infektion bedingt rasches Absterben des gesamten Knorpelstiicks. Die mit übertragenen Bindegewebszellen im Innern und die Knochenkörperchen sterben immer sofort ab. 
Es kommt also auch im besten Fall nur zu einer vorübergehenden Erholung der Knorpelzellen, niemals zu einer Weiterbildung, zum Auftreten von Mitosen oder zu einer Vermebrung innerhalb der einzelnen Knorpelhöhlen, es sind also die Bedingungen für ein Weiterleben des Knorpels nur bei Ernährung durch die die Prothesenwand penetrierende Bauchfelllymphe nicht gegeben.

\section{Literaturverzeichnis.}

Merkel, Zit. nach Marchand.

Redlfern, Ebenda.

Virch ow, Virchows Archiv, 6. Bd. S. 290.

Leopold, Ebenda. 85. Bd. 1881.

Zahn, Ebenda. 95. Bd. 1884.

Fischer, Deutsche Zeitschr. f. Chirurgie. 17. Bd.

Helferich, Ebenda. 51. Bd.

Enderlen, Ebenda. 51. Bd.

Ollier, Prudden, Salty kow, Mangoldt, Henle, Zit. nach Marchand.

Labarsch, Lubarsch-Ostertag, 1896. IU. S. 617 .

Barth, Archiv f. klin. Chirurgie. 56. Bd.

A. Schmitt, Chirargischer Kongreß. 1896.

Boeruer, Deutsche Zoitschr. f. Chirurgie. 70. Bd.

Best, Beitr. z. path. Anatomie. 1904.

Warchand, Lehre von der Wundheilung.

Moll, Zentralbl. f. Physiologie. 1899. Nr. 9. 